\title{
The Energy Performance of Vacuum Evaporators for Liquid Digestate Treatment in Biogas Plants
}

\author{
Marek Vondra*, Vítězslav Máša, Petr Bobák \\ Brno University of Technology, Institute of Process Engineering \& NETME Centre, \\ Technická 2896/2, 61669 Brno, Czech republic \\ m.vondra@vut.cz
}

Keywords: vacuum evaporation; liquid digestate; anaerobic digestion; biogas plant; energy consumption; nutrient recovery

Highlights:

- vacuum evaporation as an effective way of liquid digestate treatment in biogas plants,

- $\quad$ energy and mass balance models of three industrial evaporators suitable for digestate thickening,

- comparison of the evaporators in terms of their energy performance,

Vacuum evaporation is an efficient method for reducing the volume of liquid digestate (LD) from biogas plants (BGP). Furthermore, thickening LD in BGP contributes to the efficient utilization of waste heat and also reduces fossil fuel consumption that is needed for transporting LD. However, the utilization of vacuum evaporation must be reasonable, and a comprehensive study should precede the integration of evaporation technology in a particular BGP. For this purpose, this study compares selected parameters of three types of industrial evaporators which may be suitable for LD thickening. Furthermore, this study provides a mathematical model that describes the mass and energy balances of the chosen evaporators and is able to evaluate their energy performance for a given set of input variables.

It was concluded that the forced-circulation evaporator has the highest energy requirements and also requires a high cooling performance. This type of evaporator will be interesting for the plant owners only if the cost of power generation is extremely low. In terms of consumption of energy and cooling duty, the multi-stage flash evaporator is the most efficient and it also requires the least heat transfer area. The falling-film evaporator provides only slightly worse performance.

\section{Introduction}

One of the biggest challenges currently facing society is to decrease impact of human activities on the environment while maintaining potential for sustainable future development and the wellbeing of future generations. The European Union has been a world-leader and strong promoter of environmentally-friendly initiatives and measures. The EU has adopted the so called 20-20-20 Strategy, which aims to reduce EU carbon dioxide emissions by $20 \%$ (compared to 1990 levels), increase the share of renewable energy sources to $20 \%$, and increase efficiency in energy production by $20 \%$ (in comparison with 2007 predictions) [1].

One of the consequences of this EU policy has been an immense increase in the number of BGP. There were more than 17 thousand plants in Europe in 2015, and their total capacity exceeds $8.3 \mathrm{GW}_{\mathrm{el}}$ [2]. The BGP boom was, among others, supported by significant financial aid, which made BGP an attractive investment opportunity and facilitated the expansion of this environmentally-friendly technology.

\subsection{Waste heat in biogas plants}

Despite the above developments, BGP also has several disadvantages. One of the most significant is the ineffective use of the heat that is produced in cogeneration units. BGP generally uses only $20-40 \%$ of the heat and the rest is considered to be waste heat, and is usually not used at all [3], [4]. Yet, there are theoretically several ways to utilize the waste heat. The produced heat must be used for heating the fermentor (the main consumer of the heat). In addition to this, the heat from BGP could be used in a district heating system, drying digestate, sludge or wood sawdust, cooling, and additional power production using ORC or Kalina cycle [3]. One interesting option is the use of waste heat for heating greenhouses, in which heat consumption represents the dominant part of total crop production costs [5]. It is the distance between BGPs and industrial or populated areas which is often cited as a reason that these possible methods for utilization of the heat are rarely explored and executed. Other reasons include the quantity and quality of the heat, which ranges from $80-450{ }^{\circ} \mathrm{C}$, seasonal fluctuations in heat demands (most heat is produced in the summer) and the low price of fossil fuels [3]. The ORC process is not economically 
viable without incentives since the capital cost of installing ORC is very high and the energy efficiency is usually lower than $20 \%$ [6].

Despite this, many businesses are interested in utilizing the waste heat. If they are efficient in the way they utilize the heat, many governments will provide them with increased feed-in tariffs for electricity produced with a combination of heat and power generation. Moreover, surplus heat from cogeneration units must be cooled down, commonly in air coolers which may obviously consume more expensive electricity. The efficient utilization of heat relates to the BGP's increased efficiency as well as the plausibility of the whole concept. By fully recovering the waste heat, the environmental sustainability of biogas electricity production would improve significantly [7].

\subsection{Digestate and its treatment}

BGP owners have to face problems related to the management of large quantities of digestate. There are no accurate statistics available, but on average, 15 to 20 thousand $\mathrm{m}^{3}$ of digestate per $1 \mathrm{MW}_{\mathrm{el}}$ of installed capacity is quoted as being produced annually [8]. If the current BGP capacity in the EU 27, Switzerland, Croatia and Serbia amounts to $8.3 \mathrm{GWel}_{\mathrm{el}}$ [2], digestate production in these countries accounts for more than 120 million $^{3}$. Digestate is a by-product of anaerobic digestion, and preserves minerals from the original materials (mainly nitrogen, potassium, phosphorus, sulphur, calcium and magnesium). It is for this reason that it mostly serves as a fertilizer. For some types of plants, digestate can be more beneficial than conventional mineral fertilizers. Generally, it can be claimed that, in terms of yield, digestate is somewhere between synthetic fertilizers and livestock manure [9]. However, nutrient concentrations in the digestate are rather low. Digestate leaving the fermentor commonly contains only between 1.7 to $11.5 \%$ of dry matter, the rest is water [10]. Several reasons can be given for why plant owners aim to reduce the amount of water from the digestate, and thus reduce its volume and increase its nutrient concentrations.

The foremost reason is transport and storage costs. Transport costs may amount up to $40 \%$ of all costs incurred for small and medium-size BGPs, and their reduction is obviously very much desired [11]. Reducing the demand for digestate transport means a reduced consumption of fossil fuels that are used by the transport and application technique. Legislation may provide other motivation; operators have limited use of agricultural fertilizers in order to protect the quality of surface and ground water [12]. In this respect, Nayal et al. [13] have concluded that $\mathrm{N}_{2} \mathrm{O}$ emmissions connected with digestate's application as an organic fertilizer are by far the largest contributors to global warming in all of the BGP's life cycle stages. Certain areas with intensive animal and plant production generate a surplus of digestate [14]. The owners are then forced to transport it to distant places or have it processed in waste water treatment plants. Both options have a significant cost.

The thickening of digestate and nutrient recovery has become a topical issue and much research has been done trying to come up with reasonable solutions. The basic digestate processing method is mechanical separation of digestate into solid and liquid fractions. Processing is done using belt filters, screw presses, or decanter centrifuges. These methods were thoroughly explored by Hjorth et al. [15]. The solid fraction in the digestate contains more than $18 \%$ of dry matter (depending on the technology) and LD contains typically 2-6\% of dry matter and accounts for most of the original digestate volume. Solid components contain notable amounts of phosphor and ammonia, but in a stable form that is not available to plants [16]. The solid fraction of the separation may be directly applied onto the field, composted or further dried [12] and combusted [17], pyrolised [18], [19] or carbonized [10]. After combustion, the remaining ashes may be processed for phosphorus recovery. Extraction processes used for this purpose can be subdivided into thermochemical and wet-chemical technologies [20]. Alternatively, dried digestate can be used as a cheaper substitute for synthetic fillers for solid surface materials [21].

Most nutrients remain in the LD which makes up most of the original digestate volume (up to 90 percent). This is the reason why the LD processing is a major problem for all BGPs that perform the mechanical separation. Recycling in the anaerobic digestion process [22], ammonia stripping [23], membrane technologies such as nanofiltration and reverse osmosis [24], vacuum evaporation [25] or their combination [26] are frequently used technologies for the consecutive treatment of $\mathrm{LD}$. $\mathrm{NH}_{4}+$ and $\mathrm{P}$ recovery is also possible using selective adsorption via porous materials such as zeolites, clays, and resins [20]. Nutrients from LD can be efficiently extracted during microalgae cultivation, which provides high-value biomass for biorefinery applications and is also capable of $\mathrm{CO}_{2}$ fixation and accumulation. However, further research is needed for the wider use of the technology [27]. Apart from its general use as a fertilizer in the agricultural sector, digestate-based products may be exploited as a soil amendment on the non-agricultural consumer market [28]. The costs of some of the aforementioned technologies (in relation to the distance between the fertilized lands and transport costs) are considered in [12]. Evaporation seems to be a reasonable choice when utilizing waste heat.

Vacuum evaporation is a long standing and well tested technology used for thickening (concentrating/reducing volume) many types of processes and waste waters. The major benefits of the technology include its operational reliability and robustness. On the other hand, major drawbacks include its high energy consumption, especially heat energy, which reaches hundreds of $\mathrm{kWh}_{\text {th }}$ per $\mathrm{m}^{3}$ of the distillate. Considering the fact that there is usually a heat surplus in BGPs, at practically no cost, this drawback then becomes a benefit. The low-temperature nature of waste heat further enhances its potential for vacuum evaporation in BGP since the waste heat is mostly available as hot water used for cooling cogeneration units (at a temperature of $85-90^{\circ} \mathrm{C}$ ). This temperature is sufficient for 
evaporation under decreased pressure and at a low boiling point. Therefore, vacuum evaporation is a technology that can solve both of the above problems; the use of waste heat and the large volume of LD.

\subsection{Vacuum evaporation of digestate: state of the art}

Available studies and papers dealing with use of vacuum evaporators in agriculture usually only list evaporation as one of the methods for thickening LD and slurry. However, information about operational parameters and types of evaporators are scarce. Rehl and Müller [29] assess evaporation of the digestate in relation to a life-cycle assessment, yet there is no operational information in the text. The same relates to a study by Heviánková et al. [16] who demonstrated the option to reduce the volume of LD by evaporation down to 15 percent of its original volume. Flotats et al. [30] provide facts about the economy of a plant processing slurry from animal production. The plant incorporates vacuum evaporation but the authors fail to give any technical information about the evaporation process. Hjorth et al. [15] warn against the release of ammonia and volatile fatty acids into the condensate. The authors further mention the possibility to reduce the volume of animal slurry down to 92 percent using a one- or more-stage vacuum evaporator. Heat consumption reaches $120-130 \mathrm{kWh} / \mathrm{t}$ of the processed slurry (based on Pedersen [31]).

Melse and Verdoes [32] researched the economy and quality of products from processing liquid pig slurry combined a with vacuum evaporator (using compressed steam), mechanical separation and ammonia stripping. The combination of these technologies proved to be the most expensive solution, although no concrete data from operation of the evaporator were available. Drosg et al. [12] mentioned evaporators with forced or natural recirculation as being the most common type of evaporators for LD thickening. This type of evaporators may be arranged in three stages with a temperature gradient of 80 to $55^{\circ} \mathrm{C}$. They are able to reduce the original digestate volume by 50 percent; the dry matter concentrations reached 10 to 12 percent (max. 15 percent) and the heat consumption reached $300-350 \mathrm{kWh} / \mathrm{m}^{3}$ of the distillate.

Tampio et al. [26] compared evaporation as a technological part of several scenarios (stripping and reverse osmosis included). The authors used other researchers' data in order to determine the mass and heat balance of the evaporation. The LD was heated to $80^{\circ} \mathrm{C}$ prior to the evaporation and electricity consumption was set to $5 \mathrm{kWh} / \mathrm{t}$ of the processed LD. A combination of evaporation and reverse osmosis proved to be the most energy-efficient solution; the efficiency increased along with rising transport distances. Flotats et al. [33] describe vacuum evaporation as one of the technologies in the whole series of slurry processing. The authors name two- and morestage chamber evaporators as the most common types of the processing equipment. The study presents $25-30$ percent of dry matter in the concentrate and a specific consumption of the pilot unit at $21 \mathrm{kWh}_{\text {el }}$ and $107-353 \mathrm{kWh}$ th per $\mathrm{m}^{3}$ of the processed slurry for a flow rate of $0.5 \mathrm{~m}^{3} / \mathrm{h}$. Estimates for a higher capacity $\left(6-8 \mathrm{~m}^{3} / \mathrm{h}\right) \mathrm{show}$ a consumption of $250-280 \mathrm{kWh} / \mathrm{m}^{3}$. It is, however, unclear, what kind of energy this concerns.

Other studies directly describe the results of experiments. Guercini et al. [34] discuss a semi-continuously running pilot unit in BGP. A one-stage evaporator with forced recirculation and falling film consumed $0.87 \mathrm{kWh}$ of heat per $\mathrm{kg}$ of condensate. The final concentration of dry matter was 12 percent, as opposed to 4.2 percent on the inlet. The average flow rate of LD was $140 \mathrm{~kg} / \mathrm{h}$, and the digestate was heated with $90^{\circ} \mathrm{C}$ cooling water. The paper is unclear as to what the temperature of the LD at the inlet of the evaporator chamber was and it further does not say which appliances were included in the pilot unit's total installed capacity of $14 \mathrm{~kW}$ el. The authors admit that the efficiency of the evaporation was reduced by fouling of the heat-exchanging surface.

Operation of a laboratory semi-continuous evaporator was studied by Chiumenti et al. [35], specifically in terms of the evaporation products' quality. The authors researched one-stage and two-stage evaporators in which their construction of each of the stages differed (100 and 25 litres). Concentrations of dry matter reached 15 percent in the concentrate from the one-stage evaporator and evaporation occurred at $35^{\circ} \mathrm{C}$. The conditions of the experiment cannot compare to a full-scale plant but the authors estimate that the specific power consumption could reach 5-8 $\mathrm{kWh} / \mathrm{m}^{3}$ of LD and specific heat consumption could be $350 \mathrm{kWh} / \mathrm{m}^{3}$ of the condensate. Bamelis et al. [36] examined full-scale vacuum evaporator with $25 \mathrm{~m}^{3}$ of treated LD per day and an average thermal consumption of $165 \mathrm{~kW}$. The overall electrical consumption of the technology, $0.025 \mathrm{kWh} / \mathrm{m}^{3}$ of digestate, must be considered as a typo. With a small scale, laboratory type vacuum evaporator, Jiao et al. [37] reached an evaporation capacity of $8324 \mathrm{~mL} /\left(\mathrm{m}^{2} \cdot \mathrm{h}\right)$ at $67^{\circ} \mathrm{C}$ and $25 \mathrm{kPa}$. Electricity was the main source of heat for the testing.

Other experiments primarily focused on the quality of the products without any detailed research into the energy requirements of the process [38], [39] and [40]. In all cases, it has been confirmed that the main pollutant in the distillate is ammonium nitrogen and its concentration decreases with the decrease of $\mathrm{pH}$.

The resources above prove that vacuum evaporation is a viable technological solution for thickening LD produced in BGPs, and is already employed in many plants. Although the available studies present a lot of interesting data and conclusions, their transfer into real premises is limited and provides plant owners with only basic background information. The studies present specific energy consumptions which may be helpful only when they are supplemented with the concrete arrangement of an evaporator, its integration within the BGP, particular operating conditions and properties of the processed digestate. Without this information, the mass and energy balance cannot be done, however, it is crucial for the economic evaluation of a project. This article offers all these important data and answers decisive questions. The conclusions of this work can be used by researchers in the field of life cycle assessment. The data and information provided may also be utilized in studies related to a comparison of different 
technologies for digestate treatment. The plant owner/designer will get a complex set of information and equations that respect the specific nature of the BGP and the concrete type of evaporator. This is essential for the economic evaluation of a project. The information provided here can be used for designing a new BGP or for revamping an older one.

The main inputs for the study are:

an extensive literature survey (chapter 1.3),

- a research study of industrial evaporators for waste water treatment, which provides an idea of what the energy requirements of the commercially available products are (chapter 3 ),

- $\quad$ experimental research of the authors partly published in Vondra et al. [41].

The authors will present concrete evaporators and equations for the mathematical modelling of the process based on the mass and energy balances. They will further specify boundary conditions of the calculations, specifically, the operating parameters of the vacuum evaporators which are typical for evaporating LD and its integration into the BGP. The results of the calculations for the specific operating conditions will be evaluated and compared to the parameters of commercially available evaporators. The main focus will be on the required heat transfer surface and the specific consumption of electricity and heat.

The two main results of the study are a knowledge foundation for designing specific types of evaporators and their basic operating parameters. With this kind of information, the operator should be able to deduce what the real energy requirements are in concrete operating conditions and whether integration into a BGP makes sense both in technical and financial terms. The relationship among activities and results presented in this study is obvious from the Figure 1.

\section{Methodology}

The methodology is based on credible data about BGP and commercially available evaporators. The calculations performed are mainly based on balance modeling. The physical properties of the LD and typical operational parameters of the evaporators were acquired either in professional literature or are based on the authors' experience with evaporation of the digestate and other substances with similar properties. Only the following evaporators were included in the survey presented in chapter 3: evaporators specifically designated by the manufacturer for evaporating waste water (not necessarily for digestate). Operational parameters of installed evaporators are included as well as parameters listed by the manufacturers in marketing material. Publicly available materials, especially internet sites and product leaflets were the sole source of the research study.

The results which evaluates particular types of vacuum evaporators were obtained using a mathematical balance model and are purely theoretical. The model is based on the equations stated in this paper and defined input conditions. The mathematical model was developed in MS Excel 2013 and may be defined as analytical and static. The model is limited to the technology of the particular evaporators. It is assumed that the incoming LD was processed by a mechanical separator (e.g. screw press) and its composition is suitable for subsequent evaporation treatment. It is expected that all the necessary thermal energy will be available in the BGP and the production of distillate will not be affected by a lack of heat. The presented model does not describe the motion of substances and energy flows in different technological nodes and branches of BGP. The scope of the model is in Figure 2.

Only the configuration of the evaporator itself is researched here as the combination with other technologies (reverse osmosis, ammonia stripping, mechanical separator) is excluded. Balance calculations exclude the use of auxiliary chemical products, such as antifoaming products and acids for reducing $\mathrm{pH}$ solutions. With respect to their amount, the effect on the results is negligible. The heat loss of the evaporators and imperfections in evaporation (net equilibrium allowance, see for example [42]) are not considered. Thanks to the low temperatures of the process, their influence is also negligible. The study does not consider the long-term operation of the evaporators, which can be affected by fouling on functional surfaces, shutdowns, and so on. It further disregards concrete geometries, materials and structural parameters of the appliances. The study does not focus on analysing the potential quality and composition of the evaporated products (that is of distillate and concentrate). This topic may be found, for example, in [35], [40] or [39].

\section{Industrial evaporators for waste water treatment}

Thickening LD through evaporation is, in many ways, similar to thickening common types of waste water and process water. The main point of the evaporation is to separate water from the waste suspension, and thus decrease the volume of the liquid and increase the concentration of non-volatile substances. A wide range of industrial evaporators for many kinds of waste water are offered by a number of manufacturers and suppliers.

Long vertical tube evaporators with falling film or forced circulation evaporators with external heat exchangers are especially used for viscous and heat-sensitive liquids. Natural circulation evaporators (with no recirculation pumps) are suitable for less viscous liquids. Evaporators with a rising film are employed for substances prone to foamformation [43]. Agitated-film evaporators are a good solution for thickening suspension with a high dry matter content [44]. This type of evaporator decreases the viscosity of the liquid using an internal agitator. An external heat source can supply heat for the evaporation process in the form of steam (ST) or hot water (HW). Heat pumps (HP) 
and mechanical vapour compression (MVC) are other types of heat sources for the process. If there waste heat is available, the last two evaporator options previously mentioned are not so economical. Evaporators usually have 1 to 3 evaporation chambers (or more) and the more evaporation stages are included, the higher the efficiency of the process is.

The above technologies may be combined and supplemented with various features that increase the efficiency of the process (by-pass, preheating, recirculation). The classification and comparison of the available evaporators are, therefore, rather complicated. Types of heat sources, the number of evaporation stages, and the production capacity of the evaporators were selected as decisive parameters to compare commercially available industrial evaporators. Table 1 presents the results of the research study. Specific energy consumptions were determined as average values specified by the manufacturers for the given class of evaporators.

Almost 300 waste water and process water evaporator models are included in the research study (18 manufacturers). The processed data are mostly based on marketing materials of particular manufacturers and not on real operating conditions. The results relate to waste water generally and do not consider the specific physical properties of LD.

Several conclusions may be drawn from Table 1. In general, the evaporators with MVC (up to $28.2 \mathrm{kWh} / \mathrm{m}^{3}$ ) are the most energy efficient evaporators. These are followed by evaporators with HP (up to $147.5 \mathrm{kWh} / \mathrm{m}^{3}$ ). Energy intensity of HW and ST evaporators decreases along with the number of stages; heat takes up the main share of energy consumption ( 248.5 to $670.9 \mathrm{kWh} / \mathrm{m}^{3}$ of the condensate). However, if there is waste heat available, HW and ST evaporators tend to be the best solution since the electric power consumption is not burdened with additional technologies as in case of MVC and HP. Specific power consumption reaches $12.3 \mathrm{kWh} / \mathrm{m}^{3}$ for HW ST in high performance mode and a one-stage arrangement. It is clear that HP and MVC evaporators are not the best choice for BGPs. The power consumption of those units is enormous (especially of HP) and does not fit the plant owners' ambitions to sell as much electric power to the grid as possible. The above values are informative and cannot function as a rule. The performance and efficiency of evaporators always depends on the particular arrangement and operating conditions, and may differ based on the type of the evaporator. In general, an increase in capacity causes a decrease in specific energy consumption.

\section{Evaporators for liquid digestate thickening}

In order to compare evaporators suitable for thickening the LD, only technologies allowing the use of waste heat (hot water) were selected. Evaporators using vapour compression, heat pumps or mechanical features (e.g. scrappes, agitators) that increase power consumption are excluded from the comparison.

\subsection{Selection of evaporation technologies}

An industrial evaporators' design (using waste heat) may differ in various aspects. Their price and energy demands, which affects the total payback period, also vary. A list comparing all available evaporators using waste heat is basically impossible to develop, and this paper therefore focuses on comparing only 3 types of evaporators. Two types of evaporators suitable for viscous liquids were compared: an evaporator with forced liquid circulation (FCE) and a falling film evaporator (FFE). The evaporator with forced liquid circulation and one evaporation chamber requires the least amount of investment. The evaporator with a falling film and three-stage arrangement saves energy and is part of several model series currently manufactured.

A multi-stage flash evaporator (MSF) is the last type of evaporator subject to the analysis. This type of evaporator is not commonly used for processing waste water but the authors think it has many benefits which will be further explored. The authors opted for an arrangement with nine evaporation chambers with respect to the nature of the MSF evaporator and available temperature gradient when thickening the LD $\left(70\right.$ to $\left.40{ }^{\circ} \mathrm{C}\right)$. The authors in no way assert that this arrangement of the technologies are the most energy efficient designs possible, however, the authors think that the arrangement is suitable for thickening the LD. Finding the optimum configuration of particular types of evaporators may be subject to further research.

\subsection{Forced-circulation evaporator}

The evaporators with the most simple design are the single effect, forced-circulation evaporators (FCE), but they also have the lowest energy efficiency. Figure 3 shows the concrete arrangements considered in this study. The evaporation chamber (1) is supplemented with a circuit for heating waste water $(H)$ and with a condensation section (C). An external heat exchanger is better for easy maintenance. Faster liquid circulation through a pump helps decrease the apparent viscosity of the LD, and secures more intensive heat transfer. Overheated liquid enters the chamber (1) with decreased pressure and is flashed immediately. The produced vapour passes through the demister (DEM) into the condenser (C) and gives evaporation heat to the cooling water (CW). Part of the nonflashed liquid returns back to the circulation (REC) by a pump, and the rest leaves the unit in the form of a concentrate (CONC). If the liquid is required to be very concentrated, the flow rate through the circulation branch must be high.

A mathematical model of FCE was developed using the following set of equations. Heat and mass balances in the evaporation chamber were determined by Equations (1), (2), (3), (4) and (5): 


$$
\begin{aligned}
& M_{l d} \cdot c p_{l d} \cdot\left(T_{c o n c}-T_{l d}\right)+M_{d} \cdot L_{v}\left(p_{e}\right)=M_{r e c} \cdot c p_{l d} \cdot\left(T_{l d}^{\max }-T_{c o n c}\right) \\
& M_{l d}=M_{c o n c}+M_{d} \\
& M_{l d} \cdot x_{l d}=M_{c o n c} \cdot x_{c o n c} \\
& T_{c o n c}=T_{l d}^{\text {min }} \\
& p_{e}=p_{\text {sat }}\left(T_{\text {conc }}-\text { BPE }\right)
\end{aligned}
$$

Thermal power consumption of the system and heat transfer area of the exchanger in the heating circuit were given by Equation (6):

$$
P S_{t h}=M_{r e c} \cdot c p_{l d} \cdot\left(T_{l d}^{\max }-T_{c o n c}\right) / 3600=M_{h w} \cdot c p_{w} \cdot\left(T_{h w}^{\text {in }}-T_{h w}^{o u t}\right) / 3600=A_{h} \cdot U_{w-l d} \cdot L M T D_{h}
$$

Cooling duty of the evaporator and heat transfer area of the condenser were obtained from Equation (7):

$$
C D=M_{d} \cdot L_{v}\left(p_{e}\right) / 3600=M_{c w} \cdot c p_{w} \cdot\left(T_{c w}^{o u t}-T_{c w}^{i n}\right) / 3600=A_{c} \cdot U_{s-w} \cdot L M T D_{c}
$$

Overall electricity consumption and heat transfer area of the FCE were calculated using Equations (8) and (9):

$$
\begin{aligned}
& P S_{e l}=P S_{e l, w p}^{c o n c+r e c}+P S_{e l, w p}^{d}+P S_{e l, v p}+P S_{e l, w p}^{h w}+P S_{e l, w p}^{c w} \\
& A=A_{c}+A_{h}
\end{aligned}
$$

The equations listed below apply generally for all types of presented evaporators (FCE, FFE, MSF). The logarithmic mean temperature difference was set by Equation (10):

$$
L M T D=\left(\Delta T_{\max }-\Delta T_{\min }\right) / \ln \left(\Delta T_{\max } / \Delta T_{\min }\right)
$$

The specific heat capacity of the liquid digestate was estimated using Equation (11):

$$
c p_{l d, i}=c p_{w} \cdot\left(1-x_{l d, i}\right)+c p_{d m} \cdot x_{l d, i}
$$

Specific energy consumptions and the specific heat transfer surface were determined by Equations (12), (13), (14) and (15):

$$
\begin{aligned}
& s A=A \cdot 998,2 / M_{d} \\
& s P S_{t h}=P S_{t h} \cdot 998,2 / M_{d} \\
& s P S_{e l}=P S_{e l} \cdot 998,2 / M_{d} \\
& s C D=C D \cdot 998,2 / M_{d}
\end{aligned}
$$

Overall heat transfer coefficients for steam-water condensers were calculated using a correlation of El-Dessouky and Ettouney [45] (Equation 16):

$$
U_{s-w}=1 \cdot 10^{-3} \cdot\left(1617.5+0.1537 \cdot T_{\text {sat }}+0.1825 \cdot T_{\text {sat }}^{2}-0.00008026 \cdot T_{\text {sat }}^{3}\right)
$$

The electric power supply of water pumps was calculated using Equation (17):

$$
P S_{e l, w p}=Y_{w p} \cdot M /\left(\eta_{w p} \cdot 3,6 \cdot 10^{6}\right)+P S_{w p}^{m s}
$$

where $M$ stands for mass flow rate of a transported liquid; $P S_{w p}^{m s}=P S_{m s}^{v a c}$ for liquid pumped out of negative pressure and $P S_{w p}^{m s}=P S_{m s}^{a t m}$ in other cases. Finally, Equations (18), (19), (20), (21) and (22) were used to estimate the power supply of vacuum pumps:

$$
\begin{aligned}
& M_{n c g}=F_{n c g}^{1} \cdot M_{l d}+\sum_{i=1}^{S t}\left(\left(F_{n c g}^{2}-p e_{i} / 100\right) \cdot M_{d, i}\right) \\
& V_{n c g}=\frac{\left(273.15+T_{s a t}\left(p_{c}\right)\right) \cdot M_{n c g}}{273.15 \cdot \rho_{n c g} \cdot p_{c}} \\
& P S_{v p}^{p o l}=n_{p o l} \cdot 100 \cdot p_{c} \cdot V_{n c g} \cdot\left(\left(1 / p_{c}\right)^{\frac{n_{p o l}-1}{n}}-1\right) /\left(\left(n_{p o l}-1\right) \cdot \eta_{v p} \cdot 3600\right) \\
& P S_{v p}^{w}=Y_{v p} \cdot M_{v p}^{w} \cdot 3.6 \cdot 10^{-6} \\
& P S_{e l, v p}=P S_{v p}^{p o l}+P S_{v p}^{w}+P S_{v p}^{m s}
\end{aligned}
$$

\subsection{Falling film evaporator}

Falling film evaporators (FFE) are best suited to heat-sensitive substances which require a short contact with a heat-exchanging surface [44]. They are widely employed in the food, paper and chemical industries [46], as well as 
in desalination processes [47]. Film evaporation is further important thanks to its reduction in the intensity of foam formation. This is above all beneficial when handling substances such as LD, which are prone to foam formation. A 3-stage forward feed arrangement was chosen for the purposes of this paper without recirculation in each chamber, the so called once-through configuration (Figure 4). Prior to entering the first chamber (1), LD is preheated $(\mathrm{H} 1, \mathrm{H} 2, \mathrm{H} 3)$ by a condensate (D1, D2, D3) from particular stages. Upon entering the evaporation chamber, the liquid (LD) is evenly distributed into the tube side. The liquid in the form of a thin film flows along the tube walls, absorbs heat from the heating medium (water or steam), and gradually becomes thicker thanks to evaporation processes.

The part of the LD that has not been evaporated is pumped into another chamber and undergoes the same process under lower pressure and temperatures. Steam from one stage of the process serves as a heating medium in the following stage where it also condensates. Steam from the last stage (3) transfers heat to the cooling water (CW) in the condenser $(\mathrm{C})$. When designing the evaporator, it is important to keep in mind that the tube surface must be constantly wet. If not, the tubes may get fouled and the performance of the evaporator may be reduced. Insufficient flow rate may be partially changed by recirculation of the concentrate in each chamber. Energy intensity may be decreased by adding several other evaporation stages.

A mathematical model of the FFE was developed using the Equations (10) to (22) together with the following set of equations. Equations (23), (24) and (25) were used to determine thermal power consumption and heat transfer area related to chamber number 1 :

$$
\begin{aligned}
& P S_{t h}=M_{l d} \cdot c p_{l d} \cdot\left(T_{l d, 1}-T_{l d}^{h, 1}\right) / 3600+M_{d, 1} \cdot L_{v}\left(p_{e, 1}\right) / 3600 \\
& P S_{t h}=M_{h w} \cdot c p_{w} \cdot\left(T_{h w}^{i n}-T_{h w}^{o u t}\right) / 3600=A_{e v, 1} \cdot U_{w-l d} \cdot L M T D_{e v, 1} \\
& T_{l d, 1}=T_{l d}^{\max }
\end{aligned}
$$

The temperature of the LD leaving the $2^{\text {nd }}$ chamber was obtained from Equation (26):

$$
T_{l d, 2}=\left(T_{l d}^{\max }+T_{l d}^{\min }\right) / 2
$$

Cooling duty and heat transfer area of the condenser were calculated using Equation (27):

$$
C D=M_{d, 3} \cdot L v\left(p_{e, 3}\right) / 3600=M_{c w} \cdot c p_{w} \cdot\left(T_{c w}^{o u t}-T_{c w}^{i n}\right) / 3600=A_{c} \cdot U_{s-w} \cdot L M T D_{c}
$$

Temperature and mass flow rate of the LD leaving $3^{\text {rd }}$ chamber were given by Equations (28) and (29):

$$
\begin{aligned}
& T_{l d, 3}=T_{l d}^{\min }=T_{\text {conc }} \\
& M_{l d, 3}=M_{\text {conc }}
\end{aligned}
$$

Preheating the LD with a distillate from the $3^{\text {rd }}$ chamber was determined by Equation (30):

$$
M_{l d} \cdot c p_{l d} \cdot\left(T_{l d}^{h, 3}-T_{l d}\right) / 3600=A_{h, 3} \cdot U_{w-l d} \cdot L M T D_{h, 3}
$$

The equations listed below apply generally for evaporation chamber $i$. The heat balance, distillate production and heat transfer surface of each chamber were obtained from Equations (31) and (32).

$$
\begin{aligned}
& M_{d, i} \cdot L v\left(p_{e, i}\right) / 3600=A_{e v, i+1} \cdot U_{s-l d} \cdot \operatorname{LMTD}_{i+1} \\
& M_{l d, i-1} \cdot c p_{l d, i-1} \cdot\left(T_{l d, i-1}-T_{l d, i}\right)+M_{d, i-1} \cdot L_{v}\left(p_{e, i-1}\right)=M_{d, i} \cdot L v\left(p_{e, i}\right)
\end{aligned}
$$

The equilibrium pressure in each chamber was assumed to be decreased as a consequence of the boiling point elevation according to Equation (33):

$$
p_{e, i}=p_{s a t}\left(T_{l d, i}-B P E_{i}\right)
$$

Heat balance and heat transfer area in the preheating sections were determined using Equations (33), (34) and (35):

$$
\begin{aligned}
& M_{l d} \cdot c p_{l d} \cdot\left(T_{l d}^{h, i}-T_{l d}^{h, i-1}\right) / 3600=A_{h, i} \cdot U_{w-l d} \cdot L M T D_{h, i} \\
& M_{l d} \cdot c p_{l d} \cdot\left(T_{l d}^{h, i}-T_{l d}^{h, i-1}\right)=M_{d, i} \cdot c p_{w} \cdot\left(T_{s a t}\left(p_{e, i}\right)-T_{d}^{h d, i}\right) \\
& T_{d}^{h d, i}=T_{l d}^{h, i-1}+T T D
\end{aligned}
$$

Mass balances in evaporation chambers were given by Equations (37) and (38):

$$
\begin{aligned}
& M_{l d, i} \cdot x_{l d, i}=M_{l d, i+1} \cdot x_{l d, i+1} \\
& M_{l d, i}=M_{l d, i-1}-M_{d, i}
\end{aligned}
$$

And finally, overall values of the distillate's flow rate, electricity consumption and heat transfer area were given by Equations (39), (40) and (41): 


$$
\begin{aligned}
& M_{d}=\sum_{i=1}^{3} M_{d, i}=M_{l d}-M_{c o n c} \\
& P S_{e l}=\sum_{i=1}^{3} P S_{e l, w p}^{l d, i}+\sum_{i=1}^{3} P S_{e l, w p}^{d, i}+P S_{e l, v p}+P S_{e l, w p}^{h w}+P S_{e l, w p}^{c w} \\
& A=\sum_{i=1}^{3} A_{e v, i}+\sum_{i=1}^{3} A_{h, i}+A_{c}
\end{aligned}
$$

\subsection{Multistage flash evaporator}

Multistage flash evaporators (MSF) are commonly employed in the desalination industry. Despite the technology being in use for many years, its role in large-scale desalination is irreplaceable, and is still a subject for a lot of research and development [48]. The main benefits include its simple design and reliable operation [45]. The technology is not usually offered for thickening waste water and process water. However, MSF evaporators have an edge over FFE, in that evaporation does not occur on the heat transfer surface, but directly in the liquid bath due to its decreased pressure. This greatly reduces fouling and deposits. On the other hand, evaporation in the liquid bath stimulates foam formation that has to be suppressed by anti-foaming products.

A 9-stage arrangement was selected for the study with circulation of the concentrate (Figure 5). The number of stages reflects the temperature gradient; $70-40^{\circ} \mathrm{C}$. The 9 evaporation chambers are an optimum solution with regard to the typical temperature difference of $3-4{ }^{\circ} \mathrm{C}$ per stage. This type of evaporator requires concentrate circulation so that the dry matter has the desired concentration. Sufficient thickening cannot be achieved in the "once-through" arrangement [41] as the ratio of the produced distillate to the entering liquid volume is commonly 0.05 to 0.1 .

Upon entering the evaporator, the LD mixes with part of the concentrate (REC) and together they function as cooling water in condensing sections of particular chambers (CW1 to CW6). Before entering the first chamber (1), the liquid is heated $(\mathrm{H})$ by water from a cogeneration unit $(\mathrm{HW})$. Overheated liquid (LD0) enters the chamber with negative pressure inside and part of the water immediately evaporates. The produced steam leaves through the demisters (DEM) and condensates in the upper part of the evaporator (D1 to D9). It is then lead through other chambers into the distillate pump. Thickened LD flows into other chambers and, due to the constant decrease in the pressure, the LD expands and loses its volume. Steam in the last three chambers is cooled by external cooling water (CW), which reduces the temperature of the circulating concentrate (REC) and makes cooling in the first 6 stages more efficient. The performance of the MSF evaporator was determined using Equations (10) to (22) together with the following set of equations. Equations (42) and (43) were used to determine thermal power consumption and heat transfer area of the heating section:

$$
\begin{aligned}
& P S_{t h}=M_{h w} \cdot c p_{w} \cdot\left(T_{h w}^{i n}-T_{h w}^{o u t}\right) / 3600=M_{l d, 0} \cdot c p_{l d, 0} \cdot\left(T_{l d, 0}-T_{c w, 1}\right) / 3600=A_{h} \cdot U_{w-l d} \cdot L M T D_{h} \\
& T_{l d, 0}=T_{l d}^{\max }
\end{aligned}
$$

Mass balance in the 1st chamber was obtained from Equations (44) and (45):

$$
\begin{aligned}
& M_{l d, 0} \cdot c p_{l d, 0} \cdot\left(T_{l d, 0}-T_{l d, 1}\right)=M_{d, 1} \cdot L_{v}\left(p_{e, 1}\right) \\
& M_{l d, 0}=M_{c w, i}=M_{l d}+M_{r e c}
\end{aligned}
$$

Heat balance in the condensation section of chamber no the $6^{\text {th }}$ chamber was calculated from Equation (46):

$$
M_{d, 6} \cdot L_{v}\left(p_{e, 6}\right)=M_{l d, 0} \cdot c p_{l d, 0} \cdot\left(T_{c w, 8}-T_{l d+r e c}\right)
$$

Heat balances in the condensation sections of chambers 7, 8 and 9 were determined using Equations (47), (48) and (49):

$$
\begin{aligned}
& M_{d, 7} \cdot L_{v}\left(p_{e, 7}\right)=M_{c w} \cdot c p_{w} \cdot\left(T_{c w}^{o u t}-T_{c w, 8}\right) \\
& M_{d, 8} \cdot L_{v}\left(p_{e, 8}\right)=M_{c w} \cdot c p_{w} \cdot\left(T_{c w, 8}-T_{c w, 9}\right) \\
& M_{d, 9} \cdot L_{v}\left(p_{e, 9}\right)=M_{c w} \cdot c p_{w} \cdot\left(T_{c w, 9}-T_{c w}^{\text {in }}\right)
\end{aligned}
$$

Cooling duty and heat transfer area in last three chambers $(7,8,9)$ were obtained from Equation (50):

$$
C D_{i}=M_{d, i} \cdot L_{v}\left(p_{e, i}\right) / 3600=A_{c, i} \cdot U_{s-w} \cdot L M T D_{c, i}
$$

Mass flow rate of the LD leaving the 9th chamber was set from Equation (51):

$$
M_{l d, 9}=M_{\text {rec }}+M_{\text {conc }}
$$

The temperature of the mixture of recirculating concentrate and incoming LD was gained from Equation (52):

$$
M_{l d} \cdot c p_{l d} \cdot\left(T_{l d+r e c}-T_{l d}\right)=M_{r e c} \cdot c p_{l d, 9} \cdot\left(T_{l d, 9}-T_{l d+r e c}\right)
$$


The equations listed below apply generally for evaporation chamber $i$. The heat balance, distillate production and heat transfer surface of each chamber were obtained from Equations (53) and (54):

$$
\begin{aligned}
& M_{l d, i-1} \cdot c p_{l d, i-1} \cdot\left(T_{l d, i-1}-T_{l d, i}\right)+\sum_{j=1}^{i-1} M_{d, j} \cdot c p_{w} \cdot\left(T_{s a t}\left(p_{e, i-1}\right)-T_{s a t}\left(p_{e, i}\right)\right)=M_{d, i} \cdot L_{v}\left(p_{e, i}\right) \\
& M_{c w, i} \cdot c p_{c w} \cdot\left(T_{c w, i+1}-T_{c w, i}\right) / 3600=A_{c, i} \cdot U_{s-l d} \cdot L M T D_{c, i}=M_{d, i} \cdot L_{v}\left(p_{e, i}\right) / 3600
\end{aligned}
$$

The equilibrium pressure in each chamber was assumed to be decreased as a consequence of the boiling point elevation according to Equation (55):

$$
p_{e, i}=p_{s a t}\left(T_{l d, i}-B P E\right)
$$

The temperature drop across the evaporator was determined using Equation (56):

$$
T_{l d, i}=T_{l d, i-1}-\left(T_{l d}^{\max }-T_{l d}^{\min }\right) / 9
$$

Mass balances in evaporation chambers were given by Equations (57) and (58):

$$
\begin{aligned}
& M_{l d, i}=M_{l d, i-1}-M_{l d, i-2} \cdot c p_{l d, i-2} \cdot\left(T_{l d, i-2}-T_{l d, i-1}\right) \\
& M_{l d, i-1} \cdot x_{l d, i-1}=M_{l d, i} \cdot x_{l d, i}
\end{aligned}
$$

And finally, the overall values of distillate flow rate, electricity consumption, heat transfer area and cooling duty were given by Equations (59), (60), (61) and (62):

$$
\begin{aligned}
& M_{d}=M_{l d}-M_{\text {conc }} \\
& P S_{e l}=P S_{e l, w p}^{l d, 9}+P S_{e l, w p}^{l d}+P S_{e l, w p}^{d}+P S_{e l, v p}+P S_{e l, w p}^{h w}+P S_{e l, w p}^{c w} \\
& A=\sum_{i=1}^{9} A_{c, i}+A_{h} \\
& C D=\sum_{i=7}^{9} C D_{i}
\end{aligned}
$$

\subsection{Input data and boundary conditions}

In order to compare concrete evaporators for thickening LD, the authors selected input data and boundary conditions so that these reflect technical possibilities of the evaporators, physical properties of the LD and typical operating conditions in the BGP. The parameters may be classified into three categories.

Parameters A are physically determined and verified parameters, any specifications have a minimum impact on final results. This concerns the specific heat capacity of water $\left(c p_{w}\right)$, polytropic exponent $\left(n_{p o l}\right)$, density of noncondensable gases $\left(\rho_{n c g}\right)$ and thermophysical properties of water vapour, such as saturation temperature, specific heat of evaporation, and so on. These were determined in compliance with IAPWS IF-97 [49].

Parameters B are based on the authors' experience and relate especially to physical properties of LD. These differ in relation to the efficiency of the mechanical separation and, especially, the composition of the substrate processed by the BGP. Identifying particular properties of the LD is thus a rather complex task, and opens the field for various research. The maximal LD temperature $\left(T_{l d}^{\max }\right)$ was determined with respect to sustainability of the evaporation process. LD is an organic matter and thus it intensively fouls the heat-exchanging surface under high temperatures. A temperature of $70^{\circ} \mathrm{C}$ is also acceptable for maintaining a sufficient temperature gradient when heating the LD with $90^{\circ} \mathrm{C}$ hot water. The minimal LD temperature $\left(T_{l d}^{\min }\right)$ was determined with respect to viscosity that tends to significantly rise under low temperatures and high dry matter concentrations. The temperature is also beneficial for maintaining the temperature gradient in the condensing section.

It is very difficult to determine the overall heat transfer coefficient $(U)$ and thus there is a lot of space for future research. The coefficient depends specifically on viscosity, which is hard to predict and fluctuates due to the nonnewtonian nature of the LD. The authors do not think that the $U$ values could significantly misrepresent the results. They influence only the size of the heat transfer area $(A)$ and they will be important mostly for design calculations. Quantities related to the performance of the water and vacuum pumps $\left(\eta_{w p}, \eta_{v p}, P S_{m s}^{a t m}, P S_{m s}^{v a c}, P S_{v p}^{m s}, M_{v p}^{w}, Y_{v p}\right)$ may differ depending on a certain device's properties. The displacement energy $\left(Y_{w p}\right)$ of a water pump will be specified with respect to the evaporator's geometry and requirements of the plant owner on the hydraulic head. Coefficients $F_{n c g}^{1}, F_{n c g}^{2}$ compensate for the amount of non-condensable gases which will be extracted from the evaporator. They depend on the amount of gases dissolved in the LD and on the quality of the whole system's sealing. The boiling point elevation $(B P E)$ depends on composition of the LD and always ranges within decimal points or units of ${ }^{\circ} \mathrm{C}$. The terminal temperature difference (TTD) influences the size of the heat transfer area of heat exchangers and may be subject to design optimization. 
Parameters $\mathrm{C}$ may be designated as the real variables in the model that will be changed in real life operations depending on operating conditions and requirements of the BGP's owners. $M_{l d}$ roughly corresponds to an hour's production in a BGP with an installed capacity of $1 \mathrm{MW}$ el. The final dry matter concentration $\left(x_{\text {conc }}\right)$ in the LD was determined rather conservatively with respect to other studies [12], [34], [35]. The input and output temperatures of cooling water $\left(T_{c w}^{i n}, T_{c w}^{o u t}\right)$ are determined by the temperature of the ambient air and performance of the cooling tower. A list of all types of input parameters is given in Table 2.

\section{Results and discussion}

Table 3 shows operational parameters of particular evaporators for given set of input data. The output flow rate of distillate $\left(M_{d}\right)$ and concentrate $\left(M_{\text {conc }}\right)$ are identical for all three evaporators since the requirements for output concentration of dry matter $\left(x_{\text {conc }}\right)$ are the same. Figure 6 clearly shows the dependency of distillate production $\left(M_{d}\right)$ on LD flow rate $\left(M_{l d}\right)$ and the output concentration of dry matter $\left(x_{\text {conc }}\right)$. The higher the concentration of dry matter in the concentrate is $\left(x_{\text {conc }}\right)$, the higher the flow rate of the distillate $\left(M_{d}\right)$. However the increase drops compared to the low values of $x_{\text {conc }}$. This fact should be reflected in the evaporator design. Drawbacks related to high $x_{\text {conc }}$ (such as requirements on pumps, fouling, deposits, drop in the overall coefficient of heat transfer $U$ ) may outweigh the benefits of reducing the LD volume.

In order to achieve the required concentration $\left(x_{\text {conc }}=12 \mathrm{~kg} / \mathrm{kg}\right)$, liquid recirculation is necessary for FCE and MSF evaporators. The flow rate for both is high $\left(M_{r e c}^{f c e}=21,656 \mathrm{~kg} / \mathrm{h}, M_{r e c}^{m s f}=19,734 \mathrm{~kg} / \mathrm{h}\right)$ and they increase investments (tubes diameter, size of evaporator's chamber, water pump capacity) as well as operating costs (consumption of electricity $P S_{e l}$ ). These drawbacks are eliminated in a FFE evaporator where a single pass of the LD through the evaporator is enough for the required level of thickening. The consumption of electricity in FFE is elevated by pumping of LD after it passes through every chamber as this is necessary to transport the liquid into the upper part of the subsequent evaporator. The pressure drop between the chambers is insufficient for this purpose.

The consumption of electric power $\left(P S_{e l}\right)$ in FFE is further increased by high flow rates of cooling $\left(M_{c w}\right)$ and heating $\left(M_{h w}\right)$ water. The high flow rate is caused by the total energy efficiency of the FFE evaporator arrangement which is lower compared to MSF. Most of distillate in MSF evaporator condenses on the input liquid $\left(M_{\text {rec }}+M_{\text {fug }}\right)$ which is then preheated, which in turns saves heat. FFE also uses the condensing heat but only in the first two chambers. Almost a third of the distillate requires external cooling water for condensing, but the cooling water extracts a lot of energy from the system which must be then added by heat input in the first evaporation chamber.

FCE has the worst heat balance and the highest consumption of heat $\left(P S_{t h}\right)$ and cooling water $\left(M_{c w}\right)$. Due to the one-chamber arrangement of the evaporator, the heat regeneration is non-existent and almost all of the heat input of the equipment $(685 \mathrm{~kW})$ is wasted in the condenser. This fact is further reflected in the capacity of the water pump and overall electric power consumption $(26.4 \mathrm{~kW})$, which is the highest of all the evaporators (FFE: $14.4 \mathrm{~kW}$ and MSF: $14.0 \mathrm{~kW}$ ). The vacuum level in the condensers corresponds with output concentrate temperatures, and ranges from 0.066 to 0.072 bara.

Requirements on heat transfer area of FCE $\left(74.5 \mathrm{~m}^{2}\right)$ are comparable with those for MSF $\left(73.3 \mathrm{~m}^{2}\right)$ and FFE (79.9 $\mathrm{m}^{2}$ ). In general, it is a question of a trade-off between investment and operational costs. Energy efficiency could be improved by adding extra evaporation chambers, which would boost heat recovery and decrease the demand for cooling $(C D)$ and energy consumption $\left(P S_{e l}, P S_{t h}\right)$. On the other hand, every additional chamber increases requirements for heat transfer surface $(A)$ and affects initial costs significantly.

It is estimated that the lowest capital costs will be connected with the FFE. This is mainly due to the zero recirculation rate and thus reduced requirements for piping and evaporators dimensions. The FFE (as well as the MSF evaporator) has also lower overall capacity of pumps compared to the FCE. Capital costs of the MSF evaporator is expected to be about $6 \%$ higher than FFE. The MSF evaporator has higher number of stages but the lowest overall heat transfer area and low overall pump capacity even when a great amount of the concentrate must be recirculated. FCE is expected to require approximately $18 \%$ more capital than FFE thanks to the large dimensions and capacity of piping, pumps and heat exchangers. It should be added that within the defined boundary of the mathematical model the evaporation technologies are mutually interchangeable.

Using mathematical models of particular evaporators, the results were extended to various input $\left(x_{l d}=0.02-0.06\right.$ $\mathrm{kg} / \mathrm{kg}$ ) and output $\left(x_{\text {conc }}=0.06-0.16 \mathrm{~kg} / \mathrm{kg}\right)$ dry matter concentrations. The authors consider these values to be crucial for running a BGP and investors' decision-making. The influence of dry matter on the heat transfer area (Figure 7), heat consumption (Figure 8) and consumption of electric power (Figure 9) was observed. The results are presented as specific values, related to $\mathrm{m}^{3}$ of produced distillate, so that the results may be compared with those from other studies. The results prove prior conclusions and quantify them for various $x_{l d}$ and $x_{\text {conc }}$.

The specific parameters tend to drop with a decreasing $x_{l d}$ and increasing $x_{c o n c}$, (i.e with the distillate production), with one exception, the heat transfer area of MSF. One of the reasons is the application of calculation constants, which does not fully reflect the reality. We may assume that the rising amount of dry matter content in the concentrate worsens the thermal-hydraulic properties of the liquid. This will decrease the overall coefficient of heat transfer (rise of $s A$ ), decrease efficiency of the water pumps (rise of $s P S_{e l}$ ) and increase BPE (rise of $s P S_{t h}, s C D$ ). 
The influence of the input dry matter concentration $\left(x_{l d}\right)$ on the $s A$ values for MSF evaporator is contradictory to that of FCE and FFE. The reason is that with the growing amount of water to be evaporated (decreasing $x_{l d}$ ), the flow rate of recirculating LD $\left(M_{\text {rec }}\right)$ in the MSF evaporator is increasing. Thus the cooling water temperature in chambers 1 to 6 is increasing and larger $A$ is needed to transfer the necessary heat.

Specific cooling duty $(s C D)$ values were also determined but are not plotted in a figure as the results were not significantly affected by the dry matter content. For FCE and MSF evaporators the $s C D$ is constant: $668 \mathrm{kWh} / \mathrm{m}^{3}$ and $225 \mathrm{kWh} / \mathrm{m}^{3}$ respectively. For FFE the $s C D$ slightly drops with the decreasing $x_{l d}$ and increasing $x_{\text {conc }}$ and it ranges between 229 and $278 \mathrm{kWh} / \mathrm{m}^{3}$. Generally, it is obvious that values of $s C D$ are almost equal to that of $s P S_{t h}$ as most of the heat brought into the system must be removed by the cooling water.

The presented results correspond with the literary search of commercial evaporators as well as with values presented in other studies. We may compare only specific consumption of heat and electric power; there are no comparable values available for $s A$ and $s C D$. The energy requirements of FCE $\left(680-712 \mathrm{kWh}\right.$ th $/ \mathrm{m}^{3}, 25.9-30.5$ $\left.\mathrm{kWh} / / \mathrm{m}^{3}\right)$ correspond to the parameters of the less efficient one-stage evaporators in Table $1\left(671 \mathrm{kWh} / \mathrm{h} / \mathrm{m}^{3}, 26.8\right.$ $\left.\mathrm{kWh} / \mathrm{m}^{3}\right)$. They are further comparable to a study by Guercini et al. [34]. This study presents a heat input of a onestage evaporator of ca. $870 \mathrm{kWh} / \mathrm{m}^{3}$ but the efficiency of the operations was decreased by fouling of the heat transfer surface. Electric power input cannot be compared due to a lack of information.

The parameters of FFE $\left(241-319 \mathrm{kWh}\right.$ th $\left./ \mathrm{m}^{3}, 12.0-23.6 \mathrm{kWh} / \mathrm{m}^{3}\right)$ are comparable to those of three-stage commercial evaporators $\left(249-251 \mathrm{kWh} / \mathrm{th} / \mathrm{m}^{3}, 15.4-24.2 \mathrm{kWh} / \mathrm{m}{ }^{3}\right)$. According to Drosg et al. [12], a higher heat input of 300-350 $\mathrm{kWh}$ th $/ \mathrm{m}^{3}$ may be attributed to a different arrangement of an evaporator that allows for recuperating less heat. The performance of the MSF evaporator $\left(236-268 \mathrm{kWh} / \mathrm{h} / \mathrm{m}^{3}, 13.6-18.4 \mathrm{kWhe} / \mathrm{m}^{3}\right)$ corresponds to energy efficient three-stage commercial evaporators. However, the MSF evaporator is not commonly supplied by manufacturers. Moreover, this is a non-standard 9-stage design.

Performances of the FFE and MSF evaporators are also comparable to other studies, although a detailed comparison is not possible due to the lack of essential information. The energy consumptions stated by Flotats et al. [33] $\left(21 \mathrm{kWh} / \mathrm{m}^{3}, 107-353 \mathrm{kWh}_{\mathrm{th}} / \mathrm{m}^{3}\right)$ are related to $\mathrm{m}^{3}$ of processed slurry. It can be assumed that the specific energy consumptions related to distillate production will be somewhat larger. The specific heat consumption of $350 \mathrm{kWh} / \mathrm{m}^{3}$ expected by Chiumenti et al. [35] is slightly larger than the calculated values for FFE and MSF evaporators, but is probably associated with a less efficient two-stage evaporator.

It must be also stated that the comparison of electrical consumptions may be a bit misleading, as most of the researchers and manufactures do not provide any information about the appliances included in their results at all.

\section{Conclusion}

Vacuum evaporation may be the solution for the growing amount of digestate around the Europe. Thickening LD in BGP contributes to the efficient utilization of waste heat and also reduces fossil fuel consumption, which is needed for transporting LD. The utilization of LD as a fertilizer may reduce the energy intensive production of artificial fertilizers as well.

This paper compares the energy performance of three types of industrial evaporators, which may be suitable for liquid digestate thickening. The FCE evaporator has the highest energy requirements and also requires high cooling performance. The electric power consumption of FCE is especially high $\left(25.9-30.5 \mathrm{kWh} / \mathrm{m}^{3}\right)$. The authors believe that this type of evaporator will be interesting for plant owners only if the cost of electricity production is extremely low. In terms of consumption of energy and cooling water, the MSF evaporator is the most efficient and also requires the least heat-exchanging surface $\left(65-71 \mathrm{~m}^{2} / \mathrm{m}^{3}\right)$. FFE provides only slightly worse energy performance than MSF and may be recommended for LD thickening as well.

The mathematical model presented in this paper is purely theoretical, but the results it provided are comparable with other studies. The results are to be used for evaluating the integration of vacuum evaporators in BGPs, especially in terms of mass and heat balance. The mathematical model may help to conduct a sensitivity analysis and find the most significant factors that affect the energy intensity of the process. If we want a successful integration of a vacuum evaporator in the BGP, we have to further consider the special physical properties of the LD and the fact that for desired quality of the products it is necessary to implement specific adjustments ( $\mathrm{pH}$ reduction, reverse osmosis or ammonia stripping). This issues will be the subject of future research.

\section{Nomenclature:}

\begin{tabular}{llll} 
Full Scripts & \multicolumn{2}{l}{ Indices } \\
$A$ & Heat transfer area, $\mathrm{m}^{2}$ & atm & Atmosphere \\
$B P E$ & Boiling point elevation, ${ }^{\circ} \mathrm{C}$ & $c$ & Condenser \\
$C D$ & Cooling duty of cooling water, $\mathrm{kW}$ & conc & Concentrate \\
$D E M$ & Demister & $\mathrm{cw}$ & Cooling water \\
$F$ & Correction coefficient, - & $d$ & Distillate (condensate) \\
$L M T D$ & Logarithmic mean temperature difference, ${ }^{\circ} \mathrm{C}$ & $e$ & Equilibrium \\
$L_{v}$ & Heat of vaporization, $\mathrm{kJ} / \mathrm{kg}$ & $\mathrm{el}$ & Electric power
\end{tabular}




$\begin{array}{ll}M & \text { Mass flow rate, } \mathrm{kg} / \mathrm{h} \\ P S & \text { Power supply, } \mathrm{kW} \\ S t & \text { Number of evaporation effects (stages) } \\ T & \text { Temperature, }{ }^{\circ} \mathrm{C} \\ T T D & \text { Terminal temperature difference, }{ }^{\circ} \mathrm{C} \\ U & \text { Overall heat transfer coeff., } \mathrm{kW} /\left(\mathrm{m}^{2} . \mathrm{K}\right) \\ V & \text { Volume, } \mathrm{m}^{3} \\ Y & \text { Hydraulic head per mass of liquid, } \mathrm{J} / \mathrm{kg} \\ c p & \text { Specific heat capacity, } \mathrm{kJ} /(\mathrm{kg} . \mathrm{K}) \\ n & \text { Exponent, - } \\ p & \text { Pressure in an evaporation chamber, bara } \\ s A & \text { Specific heat transfer area, } \mathrm{m}^{2} / \mathrm{m}^{3} \\ s C D & \text { Specific cooling duty, } \mathrm{kWh} / \mathrm{m}^{3} \\ s P S & \text { Specific energy consumption, } \mathrm{kWh} / \mathrm{m} \\ x & \text { Dry matter content, } \mathrm{kg} / \mathrm{kg} \\ \eta & \text { Efficiency, - }\end{array}$

$\begin{array}{ll}e v & \text { Evaporator } \\ h & \text { Heating section } \\ h w & \text { Heating water } \\ i, j & \text { Effect numbers } \\ l d & \text { Liquid digestate } \\ \text { max } & \text { Maximum } \\ \text { min } & \text { Minimum } \\ m s & \text { Mechanical sealing } \\ n c g & \text { Non-condensable gases } \\ p o l & \text { Polytropic } \\ r e c & \text { Recirculation } \\ s & \text { Steam, water vapour } \\ \text { sat } & \text { Saturation } \\ t h & \text { Thermal power } \\ v a c & \text { Vacuum } \\ v p & \text { Vacuum pump } \\ w & \text { Water } \\ w p & \text { Water pump }\end{array}$

\section{Acknowledgments}

The research leading to these results has received funding from the Ministry of Education, Youth and Sports of the Czech Republic under the National Sustainability Programme I (Project LO1202).

\section{List of References}

[1] European Comission. Communication from the Comission to the European Parliament, the Council, the European Economic and Social Committee and the Committee of the Regions: Energy 2020, A strategy for competitive, sustainable and secure energy. $\operatorname{COM}(2010) 639$ final. 2010 . URL: eurlex.europa.eu/LexUriServ/LexUriServ.do?uri=COM:2010:0639:FIN:En:PDF.

[2] Eur Biogas Assoc. Number of biogas plants and total installed capacity in Europe 2010-2014. 2015. URL: european-biogas.eu/wp-content/uploads/2016/01/Graph-3-Evolution-biogas.png.

[3] Rutz D, Janssen R, Mergner R. Sustainable Heat Use of Biogas Plants: a Handbook. München: WIP Renewable Energies; 2012.

[4] Akbulut A. Techno-economic analysis of electricity and heat generation from farm-scale biogas plant: Çiçekdağı case study. Energy 2012;44:381-90. doi:10.1016/j.energy.2012.06.017.

[5] Esen M, Yuksel T. Experimental evaluation of using various renewable energy sources for heating a greenhouse. Energy Build 2013;65:340-51. doi:10.1016/j.enbuild.2013.06.018.

[6] Budzianowski WM. A review of potential innovations for production, conditioning and utilization of biogas with multiple-criteria assessment. Renew Sustain Energy Rev 2016;54:1148-71. doi:10.1016/j.rser.2015.10.054.

[7] Bacenetti J, Sala C, Fusi A, Fiala M. Agricultural anaerobic digestion plants: What LCA studies pointed out and what can be done to make them more environmentally sustainable. Appl Energy 2016;179:669-86. doi:10.1016/j.apenergy.2016.07.029.

[8] Czech Biogas Association. Strategická výzkumná agenda oboru bioplyn. 2014. URL: www.czba.cz/files/ceska-bioplynova-asociace/uploads/files/SVA_CzBA_2014_FINAL.pdf.

[9] Nkoa R. Agricultural benefits and environmental risks of soil fertilization with anaerobic digestates: a review. Agron Sustain Dev 2014;34:473-92. doi:10.1007/s13593-013-0196-z.

[10] Monlau F, Sambusiti C, Ficara E, Aboulkas A, Barakat A, Carrère H. New opportunities for agricultural digestate valorization: current situation and perspectives. Energy Environ Sci 2015;8:2600-21. doi:10.1039/C5EE01633A.

[11] Bojesen M, Boerboom L, Skov-Petersen H. Towards a sustainable capacity expansion of the Danish biogas sector. Land Use Policy 2015;42:264-77. doi:10.1016/j.landusepol.2014.07.022.

[12] Drosg B, Fuchs W, Al Seadi T, Madsen M, Linke B. Nutrient Recovery by Biogas Digestate Processing. IEA Bioenergy; 2015.

[13] Nayal FS, Mammadov A, Ciliz N. Environmental assessment of energy generation from agricultural and farm waste through anaerobic digestion. J Environ Manage 2016;184, Part 2:389-99. doi:10.1016/j.jenvman.2016.09.058.

[14] Auburger S, Wustholz R, Petig E, Bahrs E. Biogas digestate and its economic impact on farms and biogas plants according to the upper limit for nitrogen spreading - the case of nutrient-burdened areas in north-west Germany. AIMS Energy 2015;3:740-59. doi:10.3934/energy.2015.4.740.

[15] Hjorth M, Christensen KV, Christensen ML, Sommer SG. Solid-liquid separation of animal slurry in theory and practice. A review. Agron Sustain Dev 2009;30:153-80. doi:10.1051/agro/2009010.

[16] Heviánková S, Kyncl M, Kodymová J. Study and Research on Cleaning Procedures of Anaerobic Digestion Products. Geosci Eng 2014;60:39-50. URL: http://gse.vsb.cz/ojs/GSE/article/view/62. 
[17] Kára J, Koutný R. Využití fermentačních zbytků anaerobní digesce jako paliva. Biom.cz 2009;11. URL: biom.cz/cz/odborne-clanky/vyuziti-fermentacnich-zbytku-anaerobni-digesce-jako-paliva

[18] Opatokun SA, Strezov V, Kan T. Product based evaluation of pyrolysis of food waste and its digestate. Energy 2015;92, Part 3:349-54. doi:10.1016/j.energy.2015.02.098.

[19] Neumann J, Meyer J, Ouadi M, Apfelbacher A, Binder S, Hornung A. The conversion of anaerobic digestion waste into biofuels via a novel Thermo-Catalytic Reforming process. Waste Manag 2016;47, Part A:141-8. doi:10.1016/j.wasman.2015.07.001.

[20] Vaneeckhaute C, Lebuf V, Michels E, Belia E, Vanrolleghem PA, Tack FMG, et al. Nutrient Recovery from Digestate: Systematic Technology Review and Product Classification. Waste Biomass Valorization 2017;8:21-40. doi:10.1007/s12649-016-9642-x.

[21] Taurino R, Lancellotti I, Tatàno F, Carchesio M, Pozzi P. Mechanical and chemical resistance of composite materials with addition of anaerobic digestate. Compos Part B Eng 2016;92:259-64. doi:10.1016/j.compositesb.2016.02.012.

[22] Zeb I, Ma J, Frear C, Zhao Q, Ndegwa P, Yao Y, et al. Recycling separated liquid-effluent to dilute feedstock in anaerobic digestion of dairy manure. Energy 2017;119:1144-51. doi:10.1016/j.energy.2016.11.075.

[23] Guštin S, Marinšek-Logar R. Effect of $\mathrm{pH}$, temperature and air flow rate on the continuous ammonia stripping of the anaerobic digestion effluent. Process Saf Environ Prot 2011;89:61-6. doi:10.1016/j.psep.2010.11.001.

[24] Zarebska A, Nieto DR, Christensen KV, Søtoft LF, Norddahl B. Ammonium Fertilizers Production from Manure: A Critical Review. Crit Rev Environ Sci Technol 2015;45:1469-521. doi:10.1080/10643389.2014.955630.

[25] Bai X, Li Z, Yin F, Cheng S, Bai X, Zhang Y. Evaporation treatment on biogas slurry from anaerobic fermentation. Nongye Jixie XuebaoTransactions Chin Soc Agric Mach 2015;46:164-70. doi:10.6041/j.issn.1000-1298.2015.05.022.

[26] Tampio E, Marttinen S, Rintala J. Liquid fertilizer products from anaerobic digestion of food waste: mass, nutrient and energy balance of four digestate liquid treatment systems. J Clean Prod 2016;125:22-32. doi:10.1016/j.jclepro.2016.03.127.

[27] Xia A, Murphy JD. Microalgal Cultivation in Treating Liquid Digestate from Biogas Systems. Trends Biotechnol 2016;34:264-75. doi:10.1016/j.tibtech.2015.12.010.

[28] Dahlin J, Halbherr V, Kurz P, Nelles M, Herbes C. Marketing Green Fertilizers: Insights into Consumer Preferences. Sustainability 2016;8:1169. doi:10.3390/su8111169.

[29] Rehl T, Müller J. Life cycle assessment of biogas digestate processing technologies. Resour Conserv Recycl 2011;56:92-104. doi:10.1016/j.resconrec.2011.08.007.

[30] Flotats X, Bonmatí A, Fernández B, Magrí A. Manure treatment technologies: On-farm versus centralized strategies. NE Spain as case study. Bioresour Technol 2009;100:5519-26. doi:10.1016/j.biortech.2008.12.050.

[31] Pedersen KF. Strategies for nitrogen removal from liquid manure, Master's thesis, Institute of Chemistry and Physics, University of Southern Denmark, 2004. In: Hjorth, M., Christensen, K.V., Christensen, M.L., Sommer, S.G., 2009. Solid-liquid separation of animal slurry in theory and practice. A review. Agron. Sustain. Dev. 30, 153-180. doi:10.1051/agro/2009010

[32] Melse RW, Verdoes N. Evaluation of Four Farm-scale Systems for the Treatment of Liquid Pig Manure. Biosyst Eng 2005;92:47-57. doi:10.1016/j.biosystemseng.2005.05.004.

[33] Flotats X, Lyngso Foget H, Bonmatí A, Palatsi J, Magrí A, Schelde KM. Manure processing technologies. Technical Report No. Il concerning "Manure Processing Activities in Europe" to the European Commission, Directorate-General Environment. 184 pp. 2011.

[34] Guercini S, Castelli G, Rumor C. Vacuum evaporation treatment of digestate: full exploitation of cogeneration heat to process the whole digestate production. Water Sci Technol 2014;70:479-85. doi:10.2166/wst.2014.247.

[35] Chiumenti A, da Borso F, Chiumenti R, Teri F, Segantin P. Treatment of digestate from a co-digestion biogas plant by means of vacuum evaporation: Tests for process optimization and environmental sustainability. Waste Manag 2013;33:1339-44. doi:10.1016/j.wasman.2013.02.023.

[36] Bamelis L, Blancke S, Camargo-Valero MA, De Clercq L, Haumont A, De Keulenaere B, et al. Techniques for nutrient recovery from digestate derivatives. Document number: BIOREFINE - WP2 - A5 - P1, 2, 5, 8 - D. BIOREFINE; 2015. URL: www.biorefine.eu/sites/default/files/biorefinedownloads/Digestate.pdf.

[37] Jiao Y, Guan S, Li P, Wang S, He C, Li G, et al. Design and experiment on system for concentrating biogas slurry with vacuum evaporation. Nongye Gongcheng XuebaoTransactions Chin Soc Agric Eng 2015;31:72-6. doi:10.11975/j.issn.1002-6819.2015.24.011.

[38] Palatsi J, Campos-Pozuelo E, Torres M, Porras S, Flotats X. Full-scale combination of anaerobic digestion and concentration by evaporation in Garrigues (Lleida, Spain): Evaluation after 2 years of operation. ResearchGate 2005. URL: www.researchgate.net/publication/241780068 FULLSCALE_COMBINATION_OF_ANAEROBIC_DIGESTION_AND_CONCENTRATION_BY_EVAPORATION_I $N$ GARRIGUES LLEIDA SPAIN EVALUATION AFTER 2 YEARS OF OPERATION

[39] Li X, Guo J, Dong R, Ahring BK, Zhang W. Properties of plant nutrient: Comparison of two nutrient recovery techniques using liquid fraction of digestate from anaerobic digester treating pig manure. Sci Total Environ 2016;544:774-81. doi:10.1016/j.scitotenv.2015.11.172.

[40] Bonmatí A, Flotats X. Pig Slurry Concentration by Vacuum Evaporation: Influence of Previous Mesophilic Anaerobic Digestion Process. J Air Waste Manag Assoc 2003;53:21-31.

[41] Vondra M, Máša $V$, Bobák P. The Potential for Digestate Thickening in Biogas Plants and Evaluation of Possible Evaporation Methods. Chem Eng Trans - Vol 52 2016:787-92. doi:10.3303/CET1652132. 
[42] Cipollina A, Micale G, Rizzuti L. Investigation of flashing phenomena in MSF chambers. Desalination 2007;216:183-95. doi:10.1016/j.desal.2007.01.008.

[43] Coca-Prados J, Gutiérrez-Cervelló G, North Atlantic Treaty Organization, editors. Water Purification and Management. Dordrecht, The Netherlands: Springer; 2011.

[44] McCabe WL, Smith JC, Harriott P. Unit operations of chemical engineering. 5th ed. New York: McGraw-Hill; 1993.

[45] El-Dessouky HT, Ettouney HM. Fundamentals of Salt Water Desalination. Elsevier; 2002.

[46] Droegemueller P. How to optimise falling film evaporators. TCE Chem Eng 2007:42-3.

[47] Khawaji AD, Kutubkhanah IK, Wie J-M. Advances in seawater desalination technologies. Desalination 2008;221:47-69. doi:10.1016/j.desal.2007.01.067.

[48] Sowgath TM, Mujtaba I. Meeting the fixed water demand of MSF desalination using scheduling in gPROMS. Chem Eng Trans 2015;45:451-6. doi:10.3303/CET1545076.

[49] Wagner W, Cooper JR, Dittmann A, Kijima J, Kretzschmar H-J, Kruse A, et al. The IAPWS Industrial Formulation 1997 for the Thermodynamic Properties of Water and Steam. J Eng Gas Turbines Power 2000;122:150-84. doi:10.1115/1.483186. 


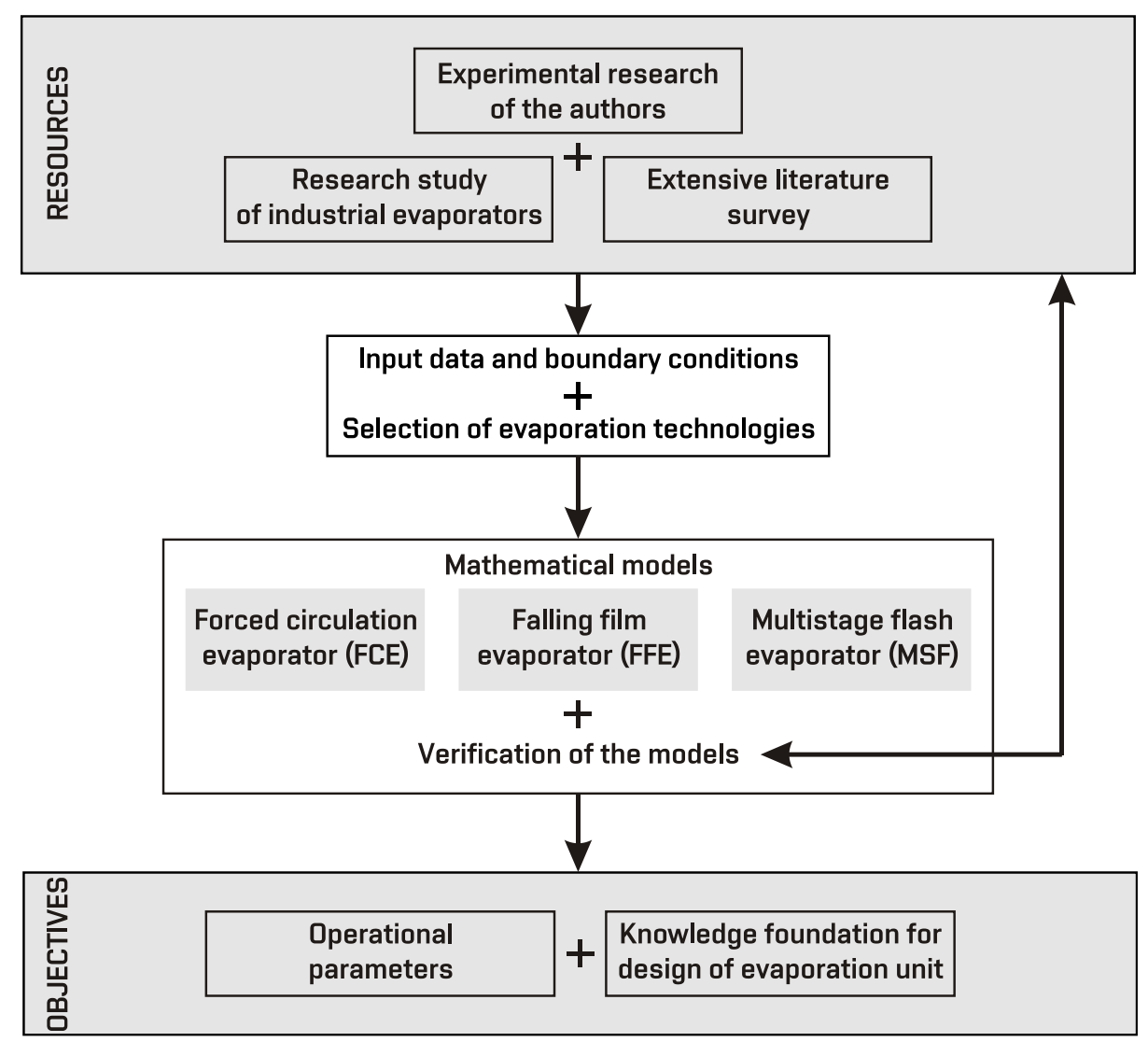

Figure 1: A research process flow chart of the study. 


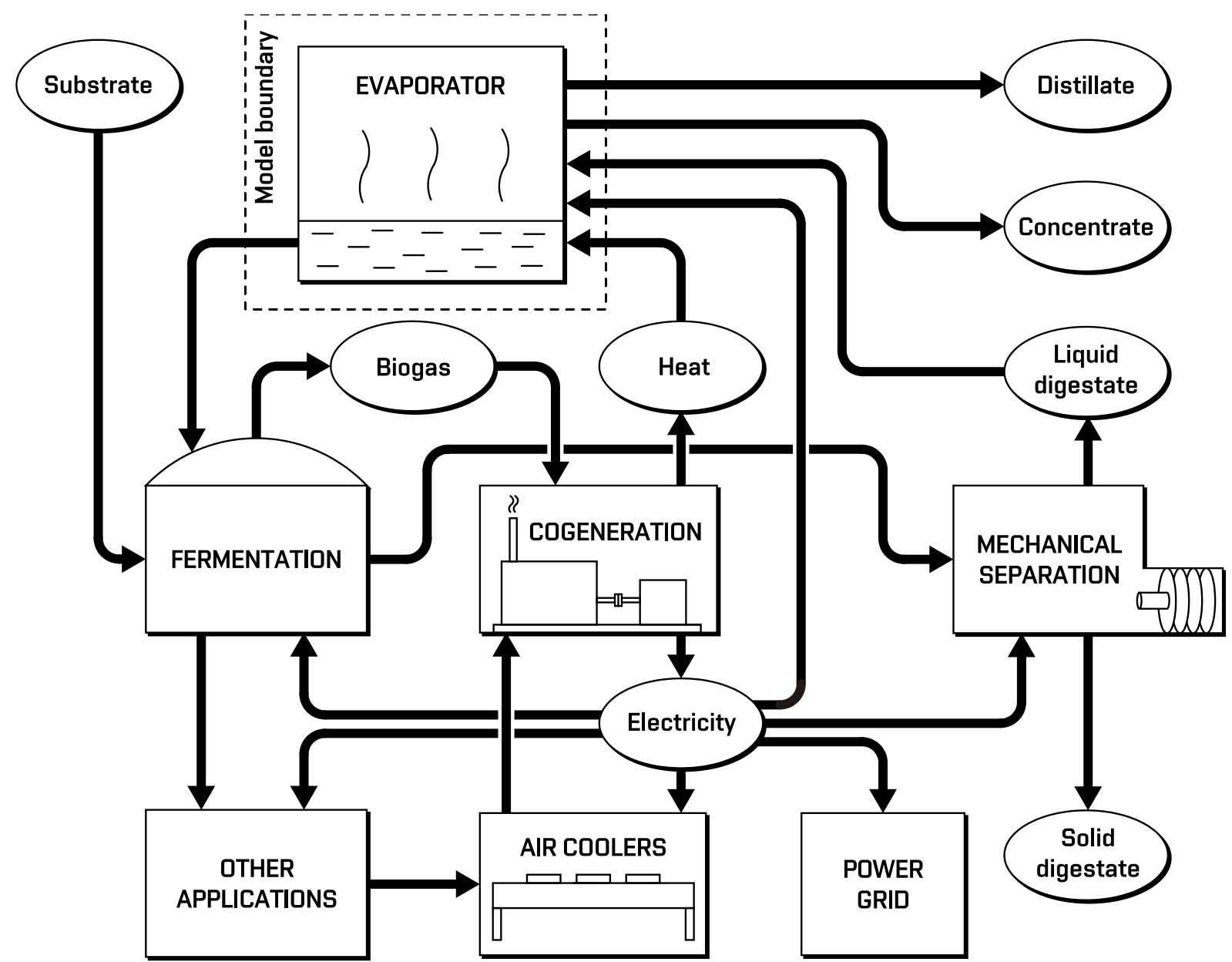

Figure 2: The boundary of the mathematical model and results based on the model. The evaporator is assumed to be positioned beyond the mechanical separation and the heat is supplied from cogeneration.

\begin{tabular}{lccccc}
\hline $\begin{array}{l}\text { Heat } \\
\text { source }\end{array}$ & $\begin{array}{c}\text { Number } \\
\text { of stages } \\
S t[-]\end{array}$ & $\begin{array}{c}\text { Flow rate } \\
\text { of distillate } \\
M_{d}[\mathrm{~kg} / \mathrm{h}]\end{array}$ & $\begin{array}{c}\text { Spec. el. en. } \\
\text { consumption } \\
s P S_{e l}\left[k W h / \mathrm{m}^{3}\right]\end{array}$ & $\begin{array}{c}\text { Spec. heat } \\
\text { consumption } \\
s P S_{t h}\left[k W h / \mathrm{m}^{3}\right]\end{array}$ & $\begin{array}{c}\text { Overall spec. en. } \\
\text { consumption } \\
s P S_{e l+t h}\left[k W h / \mathrm{m}^{3}\right]\end{array}$ \\
\hline HP & 1 & $<1000$ & 180.3 & 0 & 180.3 \\
HP & 1 & $=>1000$ & 147.5 & 0 & 147.5 \\
MVC & 1 & $<1000$ & 86.1 & 0 & 86.1 \\
MVC & 1 & $=>1000$ & 37.3 & 0 & 37.3 \\
MVC & $2-4$ & $=>3000$ & 28.2 & 0 & 28.2 \\
HW, ST & 1 & $<1000$ & 26.8 & 670.9 & 741.2 \\
HW, ST & 1 & $=>1000$ & 12.3 & 599.0 & 685.1 \\
HW, ST & 2 & $<1000$ & 26.2 & 372.0 & 398.6 \\
HW, ST & 2 & $=>1000$ & 15.1 & 360.0 & 390.0 \\
HW, ST & 3 & $<1000$ & 24.2 & 251.4 & 275.0 \\
HW, ST & 3 & $=>1000$ & 15.4 & 248.5 & 264.6 \\
\hline
\end{tabular}

Table 1: Selected parameters of evaporators for thickening process water and waste water. Specific energy consumptions are related to $\mathrm{m}^{3}$ of a distillate. 


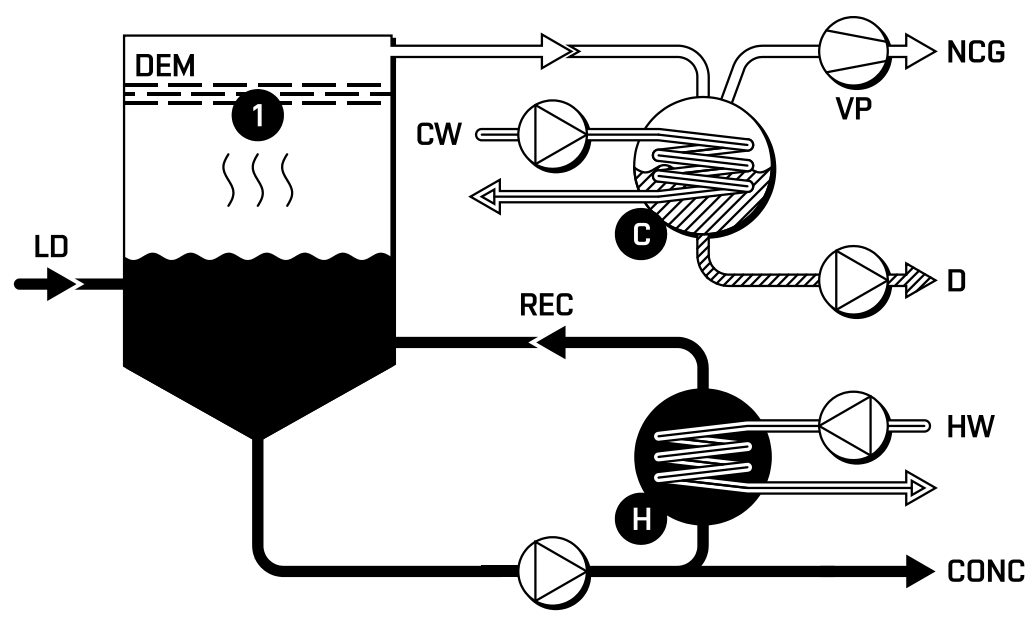

Figure 3: The design of a forced-circulation evaporator with a single evaporation chamber as it was considered in the study.

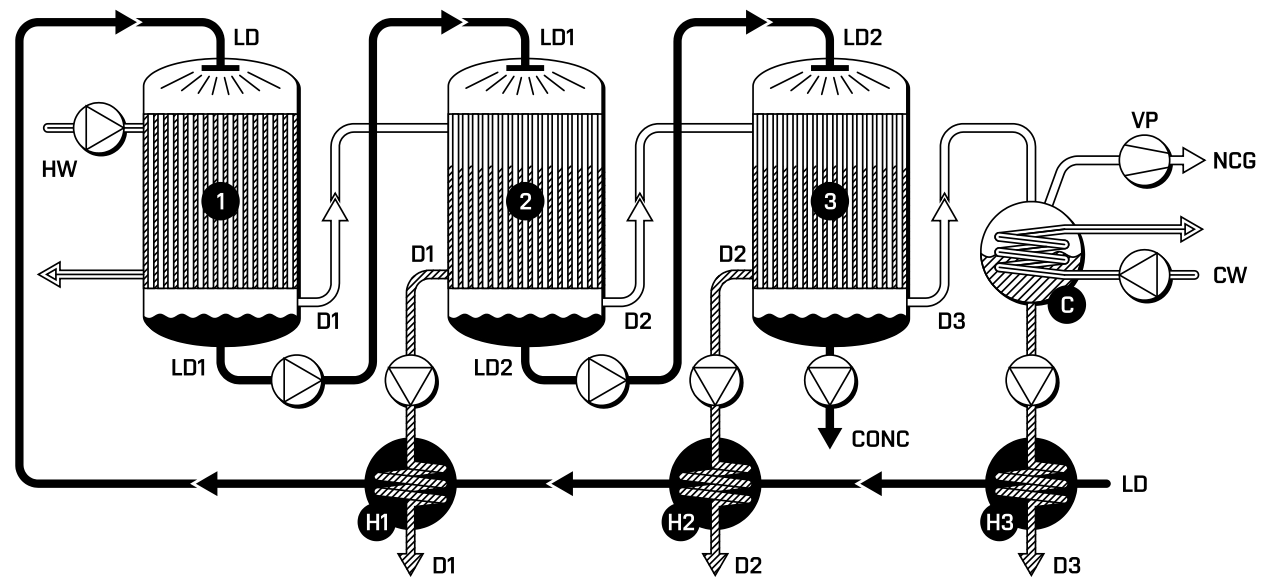

Figure 4: The design of 3-stage falling film evaporator as it was considered in the study.

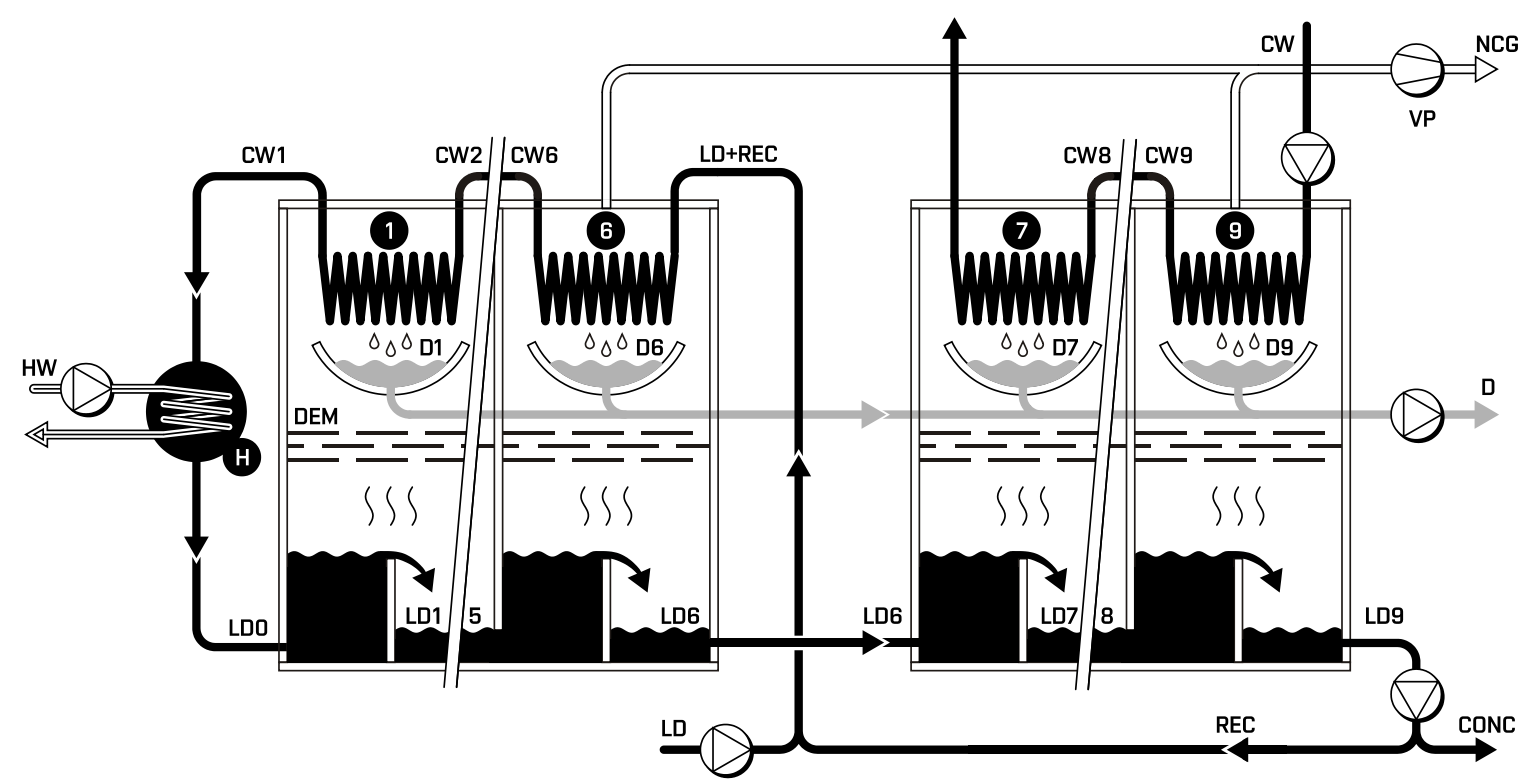

Figure 5: The design of a multi-stage flash evaporator with 9 stages and recirculation as it was considered in the study. 


\begin{tabular}{|c|c|c|c|c|c|}
\hline \multicolumn{3}{|c|}{ Type A parameters } & \multirow{2}{*}{$\begin{array}{c}\eta_{v p} \\
P S_{m s}^{a t m}\end{array}$} & \multirow{2}{*}{$\begin{array}{l}0.5 \\
0.2\end{array}$} & \multirow{2}{*}{$\begin{array}{l}- \\
\mathrm{kW}\end{array}$} \\
\hline$c p_{w}$ & 4.18 & kJ/(kg.K) & & & \\
\hline$n_{\text {pol }}$ & 1.3 & - & $P S_{m s}^{v a c}$ & 0.5 & $\mathrm{~kW}$ \\
\hline$\rho_{n c g}$ & 1.293 & $\mathrm{~kg} / \mathrm{m}^{3}$ & $P S_{v p}^{m s}$ & 0.5 & $\mathrm{~kW}$ \\
\hline \multicolumn{3}{|c|}{ Steam properties } & $F_{n c g}^{1}$ & $5 \times 10^{-5}$ & - \\
\hline \multicolumn{3}{|c|}{ Type B parameters } & $F_{n c g}^{2}$ & 0.011 & - \\
\hline$T_{l d}^{\max }$ & 70 & ${ }^{\circ} \mathrm{C}$ & $M_{v p}^{w}$ & 5400 & $\mathrm{~kg} / \mathrm{h}$ \\
\hline$T_{l d}^{\min }$ & 40 & ${ }^{\circ} \mathrm{C}$ & $T T D$ & 5 & ${ }^{\circ} \mathrm{C}$ \\
\hline$U_{w-l d}$ & 0.8 & $\mathrm{~kW} /\left(\mathrm{m}^{2} \cdot \mathrm{K}\right)$ & \multicolumn{3}{|c|}{ Type C parameters } \\
\hline$U_{s-l d}$ & 1.2 & $\mathrm{~kW} /\left(\mathrm{m}^{2} \cdot \mathrm{K}\right)$ & $M_{l d}$ & 1500 & $\mathrm{~kg} / \mathrm{h}$ \\
\hline$c p_{d m}$ & 1 & $\mathrm{~kJ} /(\mathrm{kg} . \mathrm{K})$ & $T_{l d}$ & 30 & ${ }^{\circ} \mathrm{C}$ \\
\hline$B P E_{F C E}$ & 2 & ${ }^{\circ} \mathrm{C}$ & $x_{l d}$ & 4 & $\%$ \\
\hline$B P E_{F F E}$ & $0.8 ; 1.5 ; 2$ & ${ }^{\circ} \mathrm{C}$ & $x_{\text {conc }}$ & 12 & $\%$ \\
\hline$B P E_{M S F}$ & 0.5 & ${ }^{\circ} \mathrm{C}$ & $T_{c w}^{i n}$ & 25 & ${ }^{\circ} \mathrm{C}$ \\
\hline$Y_{w p}$ & 300 & $\mathrm{~J} / \mathrm{kg}$ & $T_{c w}^{o u t}$ & 33 & ${ }^{\circ} \mathrm{C}$ \\
\hline$Y_{v p}$ & 90 & $\mathrm{~J} / \mathrm{kg}$ & $T_{h w}^{i n}$ & 90 & ${ }^{\circ} \mathrm{C}$ \\
\hline$\eta_{w p}$ & 0.5 & - & $T_{h w}^{o u t}$ & 75 & ${ }^{\circ} \mathrm{C}$ \\
\hline
\end{tabular}

Table 2: A list of input parameters used in the calculations sorted by their type.

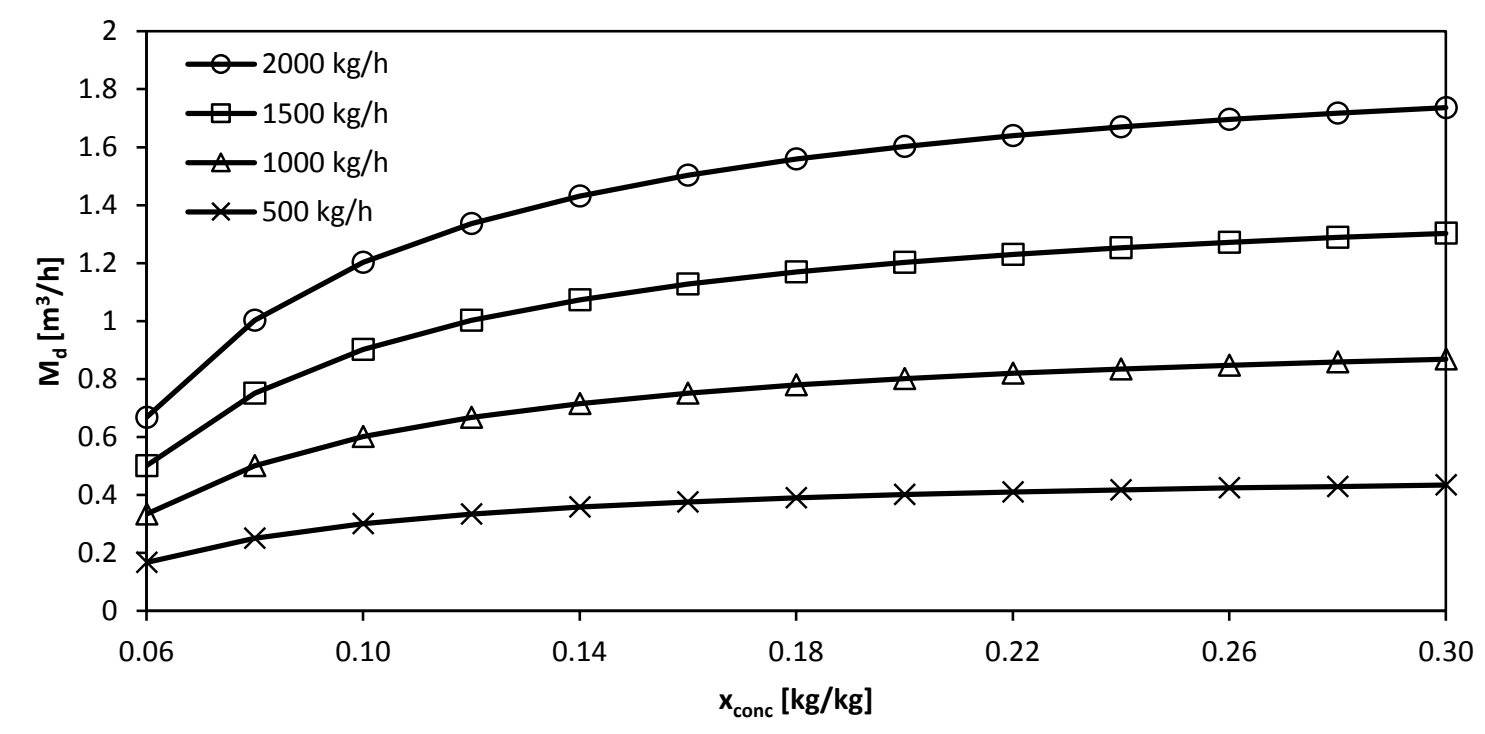

Figure 6: Distillate production of different evaporator types as a function of dry matter output concentration and $L D$ mass flow. 


\begin{tabular}{clccc}
\hline & & FCE & FFE & MSF \\
\hline$x_{l d}$ & $\mathrm{~kg} / \mathrm{kg}$ & 0.04 & 0.04 & 0.04 \\
$x_{\text {conc }}$ & $\mathrm{kg} / \mathrm{kg}$ & 0.12 & 0.12 & 0.12 \\
$M_{l d}$ & $\mathrm{~kg} / \mathrm{h}$ & 1500 & 1500 & 1500 \\
$M_{d}$ & $\mathrm{~kg} / \mathrm{h}$ & 1000 & 1000 & 1000 \\
$M_{\text {conc }}$ & $\mathrm{kg} / \mathrm{h}$ & 500 & 500 & 500 \\
$M_{\text {rec }}$ & $\mathrm{kg} / \mathrm{h}$ & 21656 & 0 & 19734 \\
$A$ & $\mathrm{~m} 2$ & 74.5 & 79.9 & 73.3 \\
$P S_{\text {th }}$ & $\mathrm{kW}$ & 685 & 277 & 225 \\
$M_{\text {hw }}$ & $\mathrm{kg} / \mathrm{h}$ & 39358 & 14412 & 12904 \\
$P S_{e l}$ & $\mathrm{~kW}$ & 26.4 & 14.3 & 14.0 \\
$C D$ & $\mathrm{~kW}$ & 670 & 262 & 225 \\
$M_{c w}$ & $\mathrm{~kg} / \mathrm{h}$ & 72093 & 28166 & 24237 \\
$p_{\text {min }}$ & $\mathrm{bara}$ & 0.066 & 0.066 & 0.072 \\
\hline
\end{tabular}

Table 3: Performance parameters of three types of industrial evaporators as were calculated for a given set of input data.

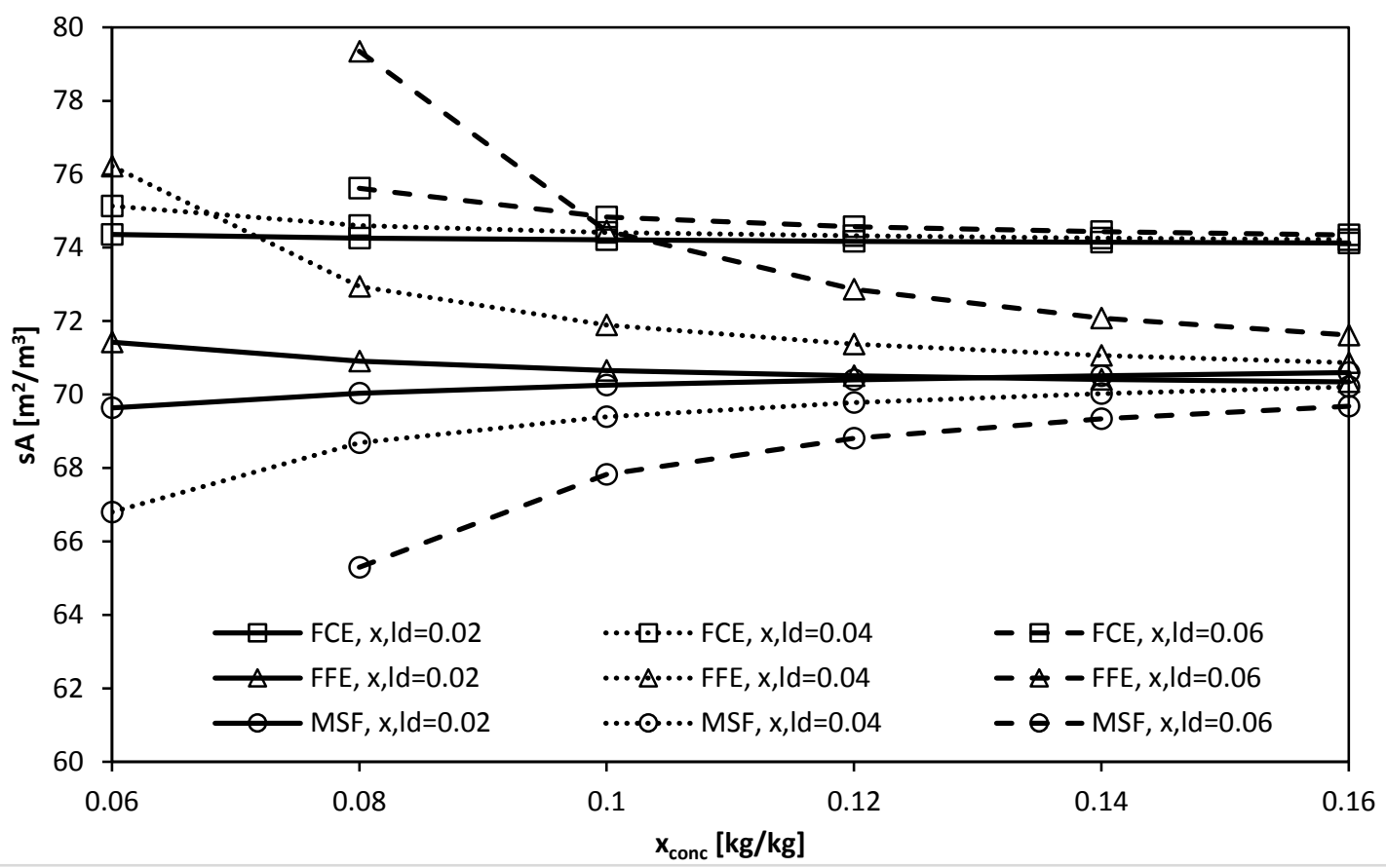

Figure 7: Heat transfer area requirements per $m^{3}$ of distillate produced as a function of $\boldsymbol{x}_{\text {conc }}$ and $\boldsymbol{x}_{\boldsymbol{l d}}$. 


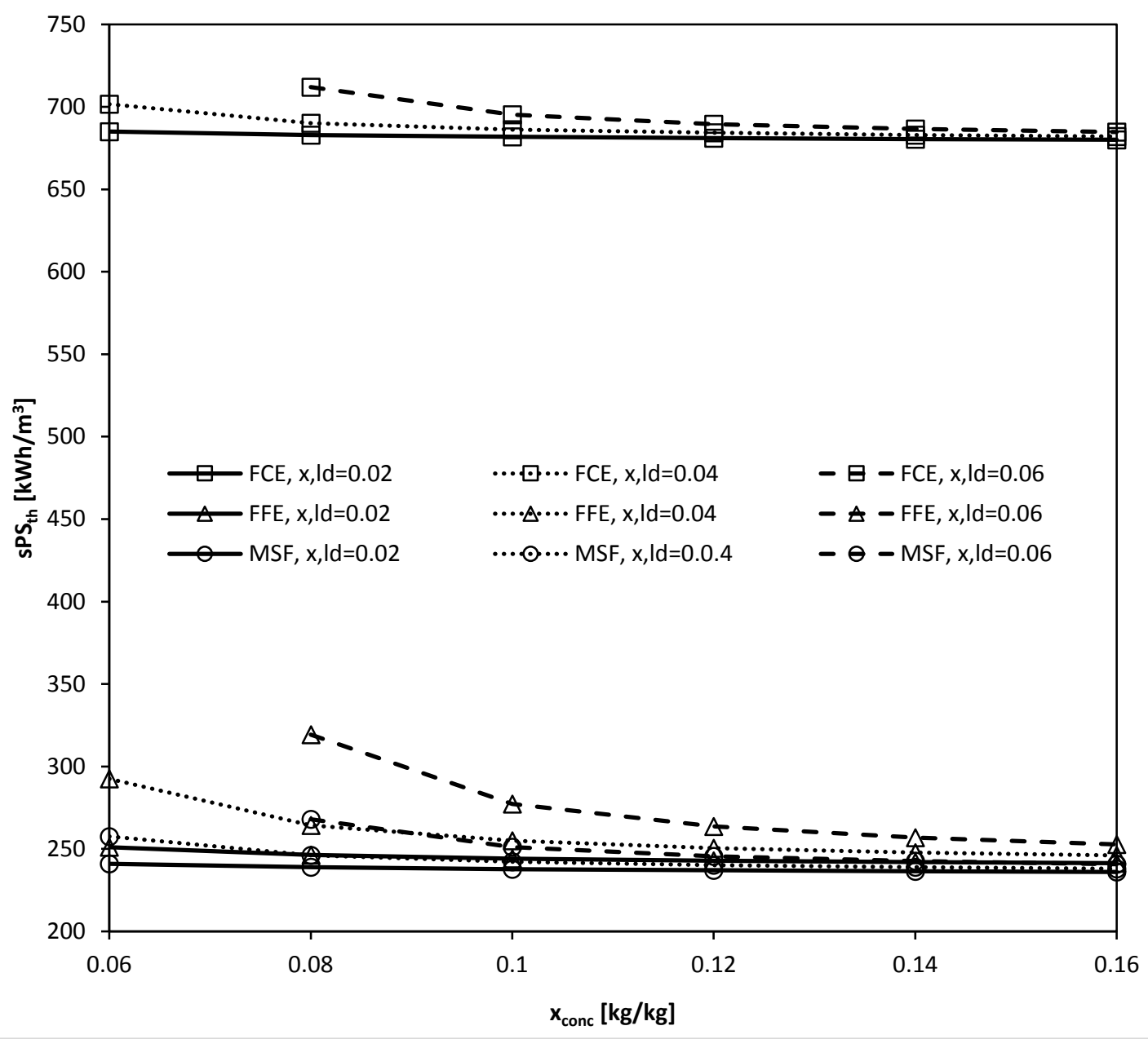

Figure 8: Thermal energy consumption per $m^{3}$ of distillate produced as a function of $\boldsymbol{x}_{\text {conc }}$ and $\boldsymbol{x}_{\boldsymbol{l d}}$.

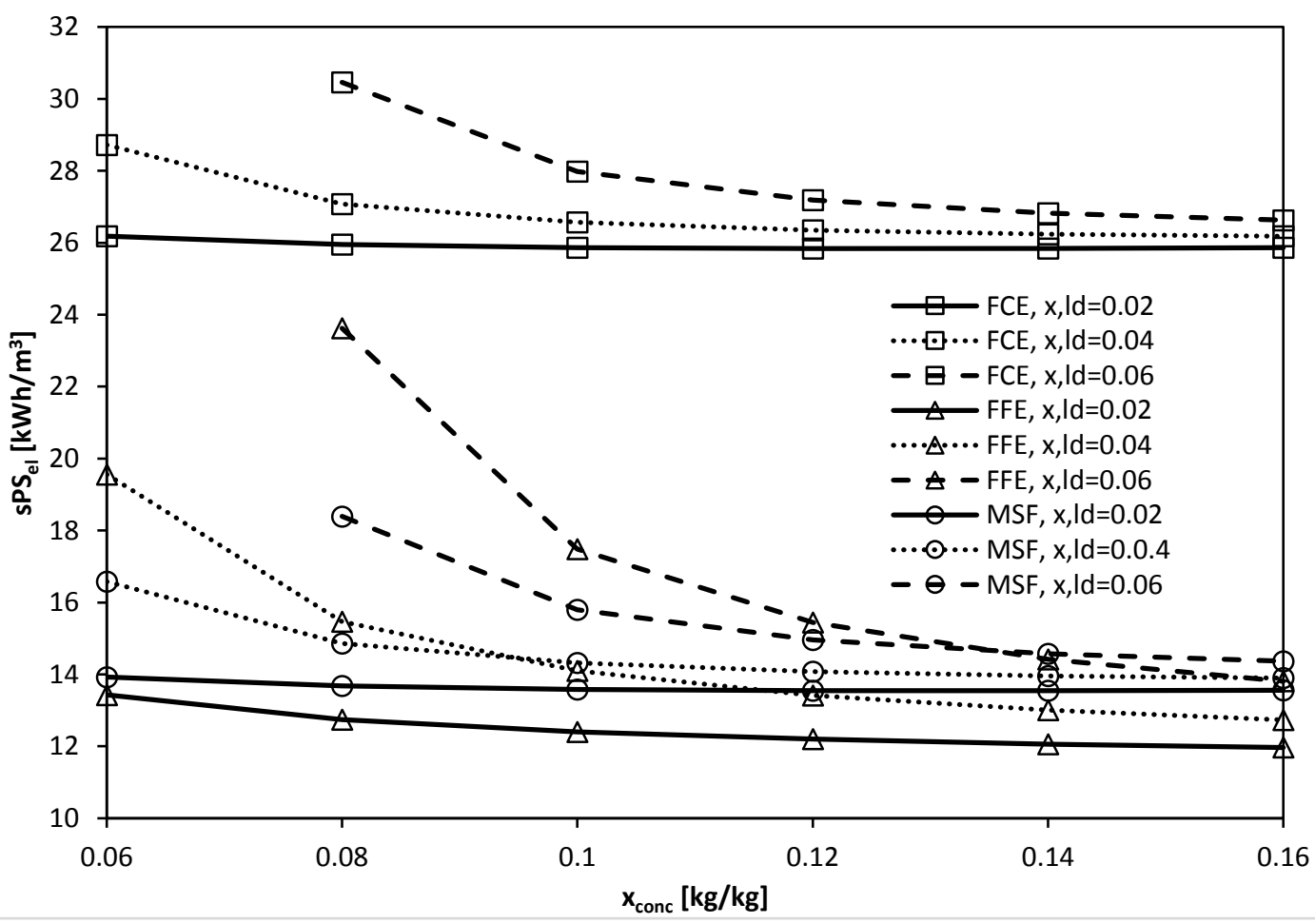

Figure 9: Electric power consumption per $\mathrm{m}^{3}$ of distillate produced as a function of $x_{\text {conc }}$ and $x_{l d}$. 